\title{
Generation, Coordination, and Evolution of Neural Circuits for Vocal Communication
}

\author{
Darcy B. Kelley, ${ }^{1}$ Irene H. Ballagh, ${ }^{1,2}$ @Charlotte L. Barkan, ${ }^{1,3}$ @Andres Bendesky, ${ }^{4}$ ๑Taffeta M. Elliott, ${ }^{1,5}$ \\ Ben J. Evans, ${ }^{1,7}$ Ian C. Hall, ${ }^{1,8}$ Young Mi Kwon, ${ }^{1,4}$ Ursula Kwong-Brown, ${ }^{1}$ Elizabeth C. Leininger, ${ }^{1,6}$ Emilie C. Perez, ${ }^{1}$ \\ (ㄴ)Heather J. Rhodes, ${ }^{9,10}$ Avelyne Villain, ${ }^{1}$ @Ayako Yamaguchi, ${ }^{1,9,11}$ and Erik Zornik ${ }^{1,3,9,11}$ \\ ${ }^{1}$ Department of Biological Sciences and Program in Neurobiology and Behavior, Columbia University, New York, New York 10027, ${ }^{2}$ Department of Zoology, \\ University of British Columbia, Vancouver V6T132, Canada, ${ }^{3}$ Department of Biology, Reed College, Portland, Oregon 97202, ${ }^{4}$ Department of Ecology, \\ Evolution and Environmental Biology and Zuckerman Mind, Brain, Behavior Institute, Columbia University, New York, New York 10027, ${ }^{5}$ Department of \\ Psychology and Education, New Mexico Institute of Mining and Technology, Socorro, New Mexico 87801, ${ }^{\circ}$ Division of Natural Sciences, New College of \\ Florida, Sarasota, Florida 34243, ${ }^{7}$ Department of Biology, McMaster University, Hamilton, Ontario L8S 4L8, Canada, ${ }^{8}$ Department of Biology, Benedictine \\ University, Lisle, Illinois 60532, ${ }^{9}$ Department of Biology, Boston University, Boston, Massachusetts 02215, ${ }^{10}$ Department of Biology, Denison University, \\ Granville, Ohio 43023, and ${ }^{11}$ School of Biological Sciences, University of Utah, Salt Lake City, Utah 84112
}

In many species, vocal communication is essential for coordinating social behaviors including courtship, mating, parenting, rivalry, and alarm signaling. Effective communication requires accurate production, detection, and classification of signals, as well as selection of socially appropriate responses. Understanding how signals are generated and how acoustic signals are perceived is key to understanding the neurobiology of social behaviors. Here we review our long-standing research program focused on Xenopus, a frog genus which has provided valuable insights into the mechanisms and evolution of vertebrate social behaviors. In Xenopus laevis, vocal signals differ between the sexes, through development, and across the genus, reflecting evolutionary divergence in sensory and motor circuits that can be interrogated mechanistically. Using two ex vivo preparations, the isolated brain and vocal organ, we have identified essential components of the vocal production system: the sexually differentiated larynx at the periphery, and the hindbrain vocal central pattern generator (CPG) centrally, that produce sex- and species-characteristic sound pulse frequencies and temporal patterns, respectively. Within the hindbrain, we have described how intrinsic membrane properties of neurons in the vocal CPG generate species-specific vocal patterns, how vocal nuclei are connected to generate vocal patterns, as well as the roles of neurotransmitters and neuromodulators in activating the circuit. For sensorimotor integration, we identified a key forebrain node that links auditory and vocal production circuits to match socially appropriate vocal responses to acoustic features of male and female calls. The availability of a well supported phylogeny as well as reference genomes from several species now support analysis of the genetic architecture and the evolutionary divergence of neural circuits for vocal communication. Xenopus thus provides a vertebrate model in which to study vocal communication at many levels, from physiology, to behavior, and from development to evolution. As one of the most comprehensively studied phylogenetic groups within vertebrate vocal communication systems, Xenopus provides insights that can inform social communication across phyla.

Key words: duets, song, hindbrain, CPG, neuroendocrine, parabrachial

\section{Introduction}

Vocal communication plays a prominent role in coordinating social behaviors of many species. Across vertebrates, a number of

Received April 1, 2019; revised Dec. 2, 2019; accepted Dec. 4, 2019.

Author contributions: D.R.K., I.H.B., C.L.B., A.B., T.M.E., B.J.E., I.C.H., Y.M.K., U.K.-B., E.C.L., E.C.P., H.J.R., A.V., A.Y., and E.Z. designed research; D.R.K., I.H.B., C.L.B., A.B., T.M.E., B.J.E., I.C.H., Y.M.K., U.K.-B., E.C.L., E.C.P., H.J.R., A.V., A.Y., and E.Z. performed research; all authors analyzed data; D.B.K. wrote the paper.

This work was supported by the Sloan Foundation, National Institutes of Health R01 NS23684, a Howard Hughes Medical Institute Professorship, a MBL Whitman Fellowship, and research funds associated with the Weintraub Chair (D.B.K.); Columbia RISE award (D.B.K. and A.B.); Searle Scholarship, Klingenstein-Simons Fellowship Award in Neurosciences, and Sloan Foundation Fellowship (A.B.); Fulbright International Science and Technology Graduate Fellowship (I.H.B.), National Science Foundation Graduate Research Fellowship Program (D.B.K., C.L.B., T.M.E.), the Natural Science and Engineering Research Council of Canada RGPIN/283102-2012 and RGPIN-2017-05770 (B.J.E.) National Institutes of Health F32 GM103266 and Revson post-doctoral fellowships (I.C.H.), a post-doctoral Fulbright Award (E.C.P.), NIH National Research Service Award Postdoctoral Fellowship NS054391, R.C. Good Fellowship (H.J.R.), National Institute of Neurological Disorders and Stroke Grant R01 NS048834, Clare Boothe Luce Professor-
CNS circuit elements and their neuromodulators that support innate features of social decision making have been identified

ship, NSF IOS 1146501,1557945 (A.Y.); NIH National Research Service Award DC6743-2, National Institutes of Health NS2091977, National Science Foundation IOS 1755423 (E.Z.). We acknowledge the key contributions of Dr. Martha Tobias (Senior Research Scientist, Columbia University, emerita) to the research trajectory described here: the initial mapping of the vocal circuit, the vox in vitro larynx preparation and mechanism of sound production, the mechanisms for sexual differentiation of the vocal neuromuscular synapse, and the characterization of vocalizations across social contexts and species.

The authors declare no competing financial interests.

Correspondence should be addressed to Darcy B. Kelley at dbk3@columbia.edu.

I.H. Ballagh's present addresses: Department of Zoology, University of British Columbia, Vancouver, V6T132, Canada.

C.L. Barkan's present address: Department of Biology, Reed College, Portland, OR 97202.

T.M. Elliott's present address: Department of Psychology and Education, New Mexico Institute of Mining and Technology, Socorro, NM 87801.

B.J. Evans' present address: Department of Biology, McMaster University, Hamilton, L8S 4L8, Canada.

I.C. Hall's present address: Department of Biology, Benedictine University, Lisle, IL 60532. 
(O'Connell and Hofmann, 2012). However, we lack a detailed neural understanding of the ways in which social signals and responses are coordinated and how these elements evolve.

Vocal production is commonly linked to hindbrain circuits that control movement of air. In fishes, sounds can be produced by contraction and relaxation of muscles associated with the airfilled swim bladder (Fine and Parmentier, 2015) driven by motor neurons at the border between hindbrain and spinal cord (Bass et al., 2008). In frogs and mammals, expiration of air from the lungs can be used to produce vibration of vocal folds, modulated by hindbrain motor neurons in nucleus ambiguus (NA; for review, see Albersheim-Carter et al., 2016). In birds, expiration-driven vibration of syringeal membranes, modulated by motor neurons in the hypoglossal nucleus, generates calls and songs (Elemans et al., 2015). Because the hindbrain also controls heart rate, blood pressure and respiration (Franklin et al., 2017; van der Heijden and Zoghbi, 2018) these vocal circuits have been particularly difficult to study in vivo in mammals, birds and terrestrial frogs. However, as described here, the aquatic frog Xenopus provides an unusual opportunity to identify CNS vocal circuits and mechanisms of sound production.

The advent of Xenopus-based pregnancy tests for human chorionic gonadotropin (hCG) in the 1930s and 1940s (Milton, 1946) led to the adoption of Xenopus as a laboratory model species and was a boon for studies of endocrinology, embryology, cell biology and development (Jacobson, 1984; Gurdon and Hopwood, 2000). This research used the South African species Xenopus laevis, which was readily maintained in laboratory breeding colonies. By injecting hCG into males and females, oocyte production and mating could be stimulated and embryos could be obtained year-round, rather than just seasonally. Subsequently, $X$. laevis reproductive behaviors, including a male- and a femaletypical call, were described (Russell, 1955), providing a foundation for future research.

Today, Xenopus provides a highly tractable system for dissecting the neural control and evolution of vocal communication. Sound predominates in social interactions of X. laevis (Fig. 1; Zornik and Kelley, 2011), and vocal behaviors have been well documented across species (Tobias et al., 2011, 2014), facilitating the phylogenetic mapping of call types (an example of Krogh's Principle: Lindstedt, 2014). Both the isolated vocal organ and the brain remain physiologically functional ex vivo for extended periods. Sexual differentiation has also been extensively investigated (Kelley, 1996; Rhodes et al., 2007) and remains plastic into adulthood (Watson et al., 1993; Potter et al., 2005) providing access to mechanistic studies of hormone action. Thus we can study vocal communication at multiple levels, including behavior, laryngeal anatomy, muscle physiology, neural circuit physiology, auditory system function, hormonal regulation, and genetics.

\section{Vocal sound production in the Pipid genus Xenopus}

In contrast to terrestrial frogs, birds, and mammals, the African frog genus Xenopus is fully aquatic, as is its sister genus Pipa from South America. The Pipid family diverged from other frogs $\sim 68$ million years ago (Cannatella, 2015; Feng et al., 2017). Vocaliza-

E.C. Leininger's present address: Division of Natural Sciences, New College of Florida, Sarasota, FL 34243. H. Rhodes' present address: Department of Biology, Denison University, Granville, $\mathrm{OH} 43023$.

A. Yamaguchi's present address: School of Biological Sciences, University of Utah, Salt Lake City, UT 84112. E. Zornik's present address: Department of Biology, Reed College, Portland, OR 97202.

https://doi.org/10.1523/JNEUROSCI.0736-19.2019

Copyright $(2020$ the authors tions are generated underwater without air movement, with one known exception (Irisarri et al., 2011). The common ancestor of Pipids and other Archeobatrachian species was terrestrial, suggesting that vocalization was initially air driven. Xenopus, and presumably all Pipids, then evolved a new mechanism of laryngeal sound production, independent of airflow, as an adaptation to re-entry to water (Kwong-Brown et al., 2019). The biomechanics of sound production have been analyzed using the ex vivo larynx experimental preparation (Tobias and Kelley, 1987; Yamaguchi and Kelley, 2000; Rhodes et al., 2007; Kwong-Brown et al., 2019).

Xenopus includes 29 described species found from Sudan to the tip of South Africa (Evans et al., 2015) in two subgenera: Silurana (4 species) and Xenopus (25 species in three groups: A, L, and M; Evans et al., 2011, 2015). As in other taxa (Mallet, 2007), inter-specifies hybridization has driven speciation at multiple points in the phylogeny (Evans et al., 2015) and accounts for allopolyploidization in this genus (Evans et al., 2005; Session et al., 2016). Xenopus is highly polyploid with chromosome numbers ranging from diploid to dodecaploid. S-group species includes the only diploid, $X$. tropicalis, and three tetraploid species. A-group species includes the higher ploidy species, whereas L-group and $\mathrm{M}$-group are tetraploids.

Because of its evolutionary history of return to water from land, Xenopus have evolved a specialized mechanism of sound production within the larynx. The sound-producing elements are two tightly apposed arytenoid cartilage discs (Fig. 2A; Yager, 1992) at the anterior end of the larynx. Action potentials of axons in laryngeal nerves (Bopp et al., 2014; Fig. 2B) leads to simultaneous contraction of paired bipennate muscles (Tobias and Kelley, 1987) connected to the discs by tendons. Contraction generates rapid separation of the discs, which creates a single pulse of sound as the larynx vibrates within the thorax, effectively coupled to the body and the surrounding water (Kwong-Brown et al., 2019). The basic vocal unit of all Xenopus calls is thus a brief sound pulse; these pulses are then combined into a variety of temporal patterns that have social meanings (Fig. 1). The most frequent vocalizations are advertisement and release calls. Males of every described Xenopus species (except X. longipes, which has not yet been recorded) produce a species-specific advertisement call distinguished by temporal pattern and spectral features (Tobias et al., 2011; Evans et al., 2015). Unlike males, females in A-group species do not release call (Tobias et al., 2014) suggesting that this behavior was lost from the most recent common ancestor of A-group species. Although the entire vocal repertoire of other species has not yet been described in detail, the relative ease of obtaining and quantifying Xenopus vocalizations allows for powerful phylogenetic comparisons.

The full vocal repertoire has been characterized in X. laevis; males and females produce and respond to calls according to social context and reproductive state (Fig. 1; Tobias et al., 1998a, 2004). The repertoire is quite complex, consistent with the role of vocalizations as the primary modality of social communication. Males produce advertisement calls when alone or in the presence of another male or a female. Sexually unreceptive females tick (their release call) when clasped while receptive females are silent (Russell, 1955; Kelley, 1982; Wu et al., 2001). When ovulation is induced by hCG injection and oviposition is imminent (Wu et al., 2001), females produce a more rapid series of sound pulses, the rapping call, in response to an advertising male (Tobias et al., 1998a). Ticking mutes the male, whereas rapping is an acoustic aphrodisiac that stimulates male answer calling (Tobias et al., 1998a; Elliott and Kelley, 2007). Sexually active males engage in 


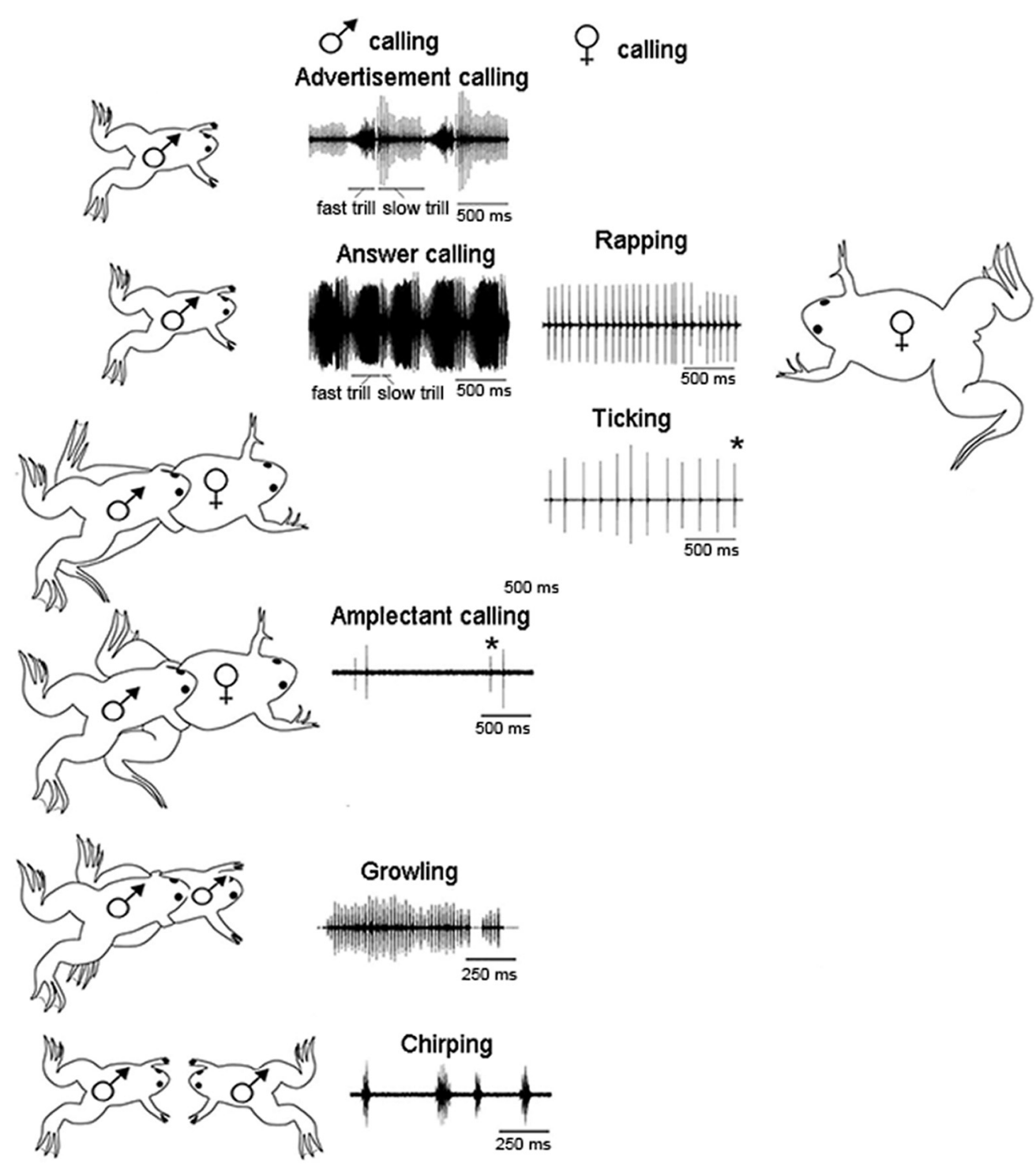

Figure 1. The vocal repertoire of $X$. laevis is sexually differentiated and specific to social context. The male advertisement call consists of individual sound pulses* at fast (60 pps) and slow ( $30 \mathrm{pps)}$ rates. Males produce advertisement calls when alone or with conspecifics. When oviposition is imminent, females produce a rapid (16 pps) series of sound pulses known as rapping. Rapping serves as an acoustic aphrodisiac and stimulates male answer calling. When clasped, sexually unreceptive females extend their hind legs and produce the slower ticking call (6 $\mathrm{pps)}$. A male clasping another frog, male or female, produces the amplectant call. A clasped male responds with growling. During the social interactions that precede one male vocally suppressing another, males produce the chirping call. Modified from Zornik and Kelley, 2011. pps: pulses per second.

vocal duels, that include the chirping call, for the right to advertise: one is silenced while the other, the vocally dominant male, continues to call (Tobias et al., 2004). Males produce an amplectant call when clasping a female and growl (their release call) when clasped by another male (Tobias et al., 2014). Call types are thus also sexually differentiated: ticking and rapping in females; growling and advertisement calling in males. Pairs of sexually active $X$. laevis sing duets consisting of alternating male answer calling (a more intense form of the advertisement call) and female rapping (Tobias et al., 1998a), a strong example of vocal-toauditory matching or "turn-taking" (Ravignani et al., 2019).

Male and female sound pulses differ in spectral components: male pulses include two dominant frequencies, $\sim 1.7$ and $\sim 2.3$ $\mathrm{kHz}$, whereas female pulses are more broadband with a peak at $\sim 1.2 \mathrm{kHz}$ (Tobias et al., 1998a, 2011). Spectral properties of female ticks and raps do not differ. Socially appropriate vocal responses of males depend on call spectral (pitch) and temporal (pattern) properties. An advertising male requires both female- specific sound frequencies and rapping rates to switch to answer calling. Chirping, in contrast, can be evoked by a male temporal pattern at either a male or female pitch (Vignal and Kelley, 2007). Female ticking transiently suppresses male calling; males habituate to ticking after $\sim 2 \mathrm{~m}$ and resume advertisement calling. Males do not habituate to rapping (Elliott and Kelley, 2007). Broadcasts of calls are as effective as a calling animal.

\section{Hormonal regulation of vocal features}

Sexually differentiated characteristics support behavioral differences. Some differences between the sexes, e.g., copulatory behaviors, are directly related to reproduction itself whereas others, e.g., courtship, though equally essential, are less directly related. Evolutionarily this second class of behaviors reflects selection driven by same sex competition for access to mates or mate attraction (intra- and inter-sexual selection; Darwin, 1872). Sexual selection often results in marked sex differences in organs used to generate courtship songs as well as the underlying neural cir- 

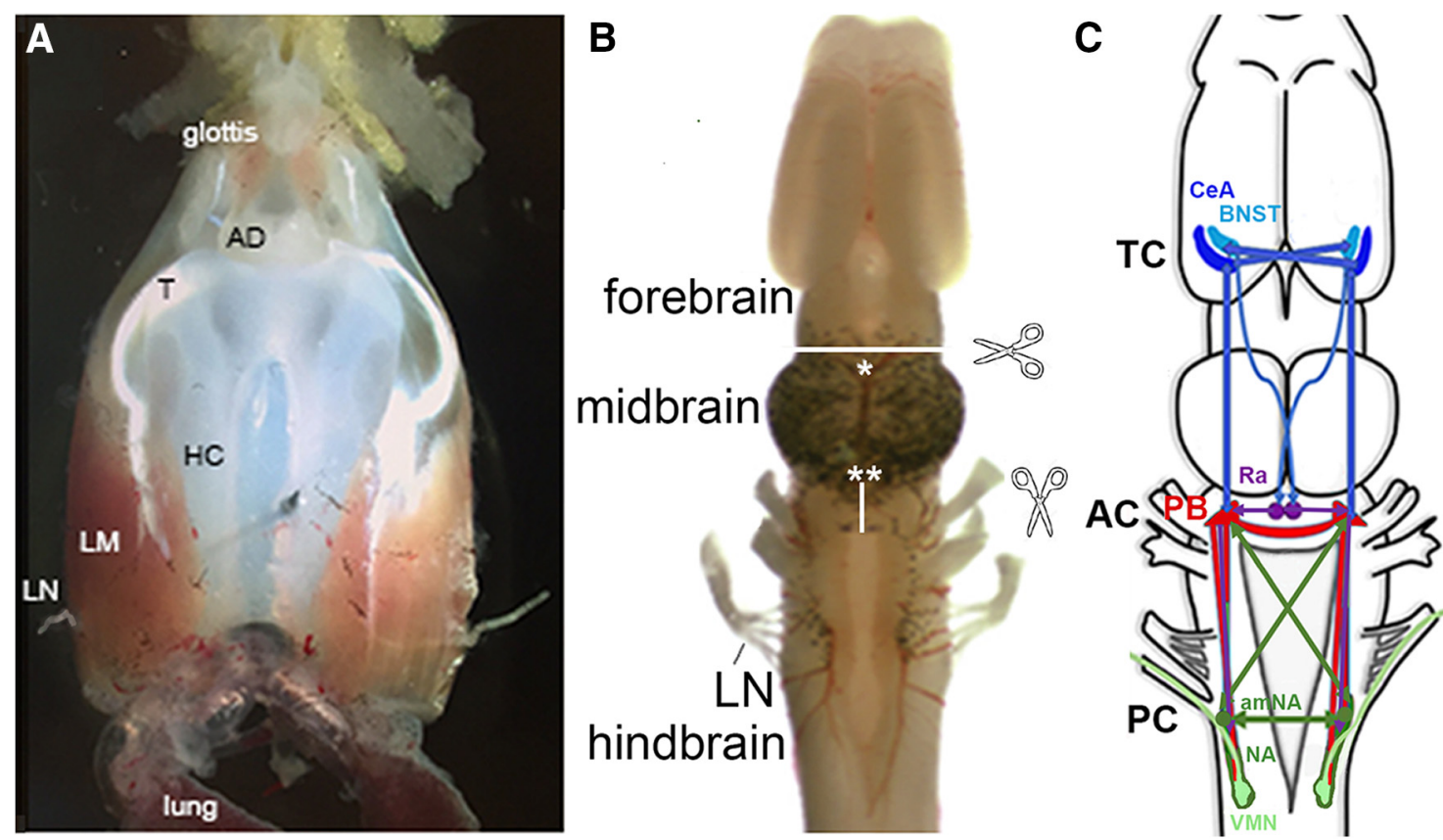

Figure 2. A, The ex vivo larynx, dorsal view; anterior is up. The larynx communicates with the oral cavity via the glottis anteriorly and with the lungs posteriorly. The sound producing elements are the arytenoid disks (ADs), which connect via a tendon (T) to intrinsic laryngeal muscles (LM), which wrap around the hyaline cartilage (HC). When the laryngeal nerves (LNs) are stimulated simultaneously, the muscles contract and, provided a critical velocity is attained, the ADs separate and a sound pulse is produced. $\boldsymbol{B}$, The ex vivo brain viewed from the dorsal surface, anterior is up. Locations of transections discussed are indicated by scissors icons, white lines, and asterisks. C, A schematic diagram of brain regions that contribute to vocal production including the CeA and BNST in the forebrain (blue), the PB (red) and amNA (green) in the hindbrain, and the raphe nucleus (purple), as well as extensive, ipsilateral and contralateral, usually reciprocal, connections between each nucleus. TC, Telencephalic commissure; AC, anterior commissure; PC, posterior commissure.

cuitry. In Drosophila (Billeter et al., 2006) and presumably other invertebrates (Bopp et al., 2014), the genes that determine gonadal sex also shape sexually dimorphic organs. In vertebrates, however, although sex is usually genetically determined as well, hormones secreted by the testes or ovaries instead direct the sexual differentiation of tissues that express the appropriate, ligandactivated transcription factor, androgen or estrogen receptor, largely regardless of genetic sex. Gonadal hormones can act during particular periods of development while tissues are forming to set into motion cellular programs responsible, for example, for a male vocal organ or for maintaining enough neurons to precisely control that organ. These steroids can also act transiently at puberty or during the breeding season, to trigger activity in sexspecific neural circuit. The two mechanisms have been described as the "organizational" and "activational" roles of androgens and estrogens (Phoenix et al., 1959). Observed sex differences in behavior in a vertebrate species might reflect current differences in circulating hormones of males and females, and/or developmental history, action on receptor expressing sensory structures and/or neurons, neural circuits or muscles that execute a sexually differentiated behavior. It is often very difficult to pinpoint exactly when and where hormones are acting. A key advantage of Xenopus for evaluating central and peripheral mechanisms underlying male- and female-specific vocal patterns has been, as described later, the ability to evoke "fictive" behavior not only from the ex vivo nervous system but also from the ex vivo vocal organ that can be induced to call in the dish (vox ex vivo; Tobias and Kelley, 1987).

Hormones shape vocal behaviors in the X. laevis at multiple levels, from forebrain command centers, to pattern generating hindbrain circuits, to the muscles themselves, and over multiple time courses, from metamorphosis to adulthood and across the breeding season. As for most vertebrate sexually differentiated behaviors, the male-specific advertisement call is activated during adulthood by androgen secreted from the testes (Wetzel and Kelley, 1983; Yang et al., 2007). Hormonal signals regulate vocal communication by acting both on the CNS and on the periphery. Gonadal steroid receptors are expressed at high levels in auditory and vocal regions in the CNS (Kelley, 1980), the peripheral auditory ganglion (Pérez et al., 1996), and in the larynx (Kelley et al., 1989). Other hormones also influence communication pathways. Gonadotropins in males, for example, act on the testis to promote androgen synthesis and secretion, and also act on neurons directly via gonadotropin receptor expression in the central nucleus of the amygdala (CeA, formerly ventral striatum; Hall et al., 2016) to stimulate advertisement calling (Yang et al., 2007). Sex differences in the vocal system remain at least partially plastic into adulthood. Adult female X. laevis that are ovariectomized and treated with testosterone produce male-like vocalizations; both laryngeal and brain function are masculinized (Hannigan and Kelley, 1986; Potter et al., 2005; Rhodes et al., 2007).

The $X$. laevis larynx is sexually dimorphic. Laryngeal muscle, both fiber type and number, as well as the neuromuscular synapse, differ in the sexes, supporting sexually differentiated temporal features of vocal behaviors. In ex vivo larynx preparations, stimulation of the laryngeal nerve produces sound pulses that spectrally match in vivo calls (Tobias and Kelley, 1987). Ex vivo nerve stimulation reveals that male laryngeal muscles can contract and relax completely at fast and slow advertisement trill rates [ $\sim 60$ and 30 pulses per second (pps), respectively]. Female laryngeal muscles can contract and relax completely at ticking and rapping stimulation rates ( $\sim 6$ and $16 \mathrm{pps}$ ) but tetanize at higher stimulation rates. Adult male laryngeal muscle is entirely fast twitch and female laryngeal muscle is mostly slow twitch in fiber type (Sassoon et al., 1987).

Laryngeal motor neurons (vocal motor neurons; Fig. 2C) in the caudal hindbrain (Nucleus Ambiguus; Fig. 3B; formerly 


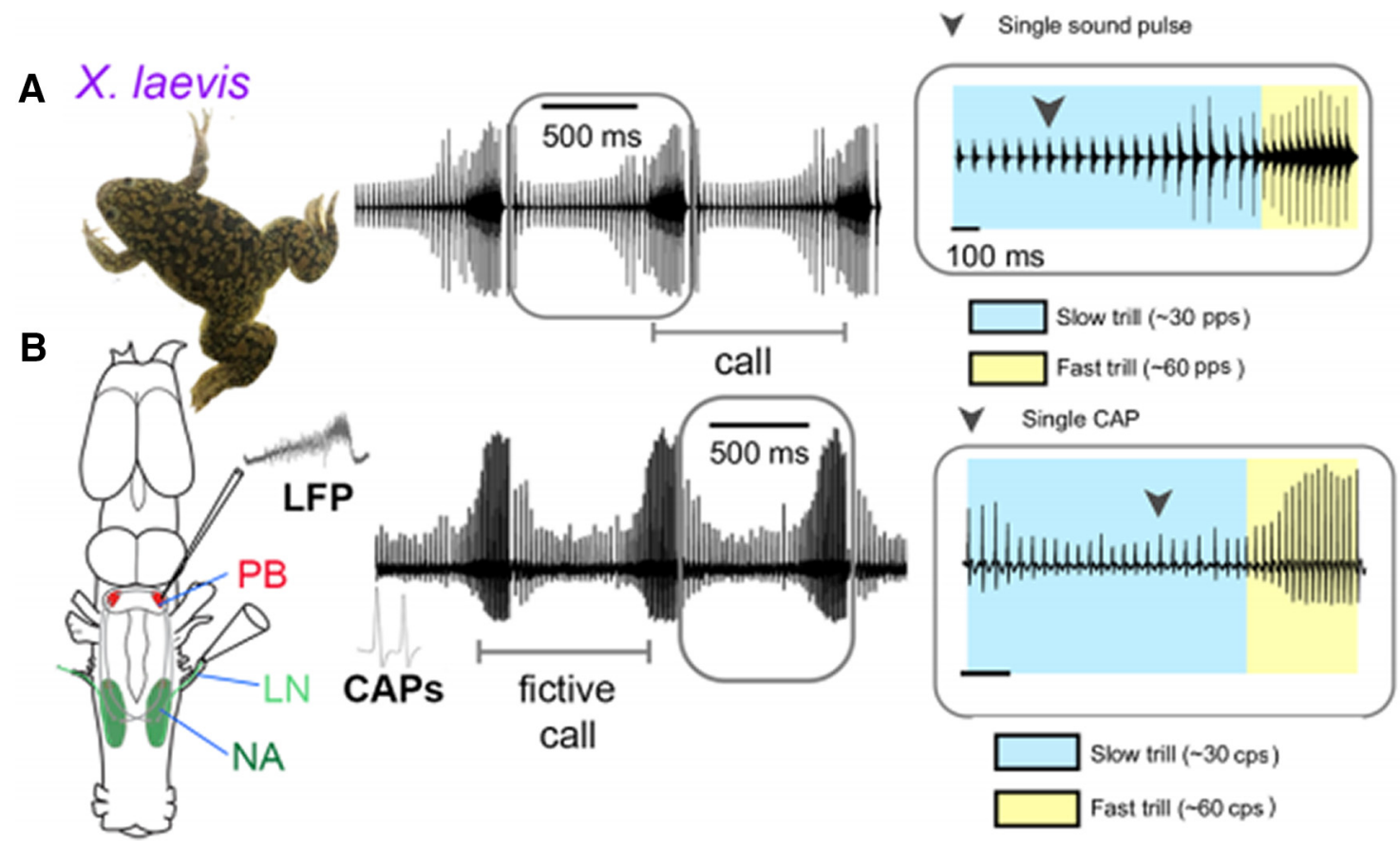

Figure 3. Actual $(\boldsymbol{A})$ and fictive $(\boldsymbol{B})$ advertisement calling in Xenopus laevis. Compound action potentials (CAPs) recorded from the laryngeal nerve correspond to pattern of actual advertisement calls. A LFP that coincides with fast trill CAPs from the laryngeal nerve (LN), can be recorded extracellularly from the PB. Modified from Barkan et al. $(2017,2018)$.

nucleus IX-X; Albersheim-Carter et al., 2016) synapse on laryngeal muscle fibers (Tobias et al., 1998b). The strength of this laryngeal synapse is also sexually differentiated. The quantal content of male neuromuscular synapses is significantly lower than that of female synapses, preventing muscle contraction in response to a single stimulus applied to the laryngeal nerve. Instead, contraction requires several consecutive spikes to facilitate effective synaptic transmission. Synaptic facilitation and progressive recruitment of vocal motor neurons (Yamaguchi and Kelley, 2000) underlie the increasing amplitude of sound pulses in the fast trill phase of male advertisement calls (Fig. 1). Male laryngeal neuromuscular synapses are thus weak and female synapses are strong in X. laevis. Stronger synapses in females are due to ovarian estrogen secretion acting on specific estrogen receptor isoforms expressed in laryngeal muscles which then transmit an as yet unidentified signal to the motor nerve terminal (Wu et al., 2003).

Laryngeal muscles strongly express androgen receptor (Kelley et al., 1989) as do vocal motor neurons (Kelley, 1980; Fig. 2C). Interneurons in anterior-medial NA, which project to the contralateral NA as well as other components of the vocal central pattern generator (CPG) also express androgen receptor (Fig. 2C; Pérez et al., 1996; Zornik and Kelley, 2007; Yamaguchi et al., 2017). In adult males, the amount of advertisement calling is reduced 2 weeks after castration (Wetzel and Kelley, 1983) and essentially abolished $\sim 5$ months later when laryngeal muscle is demasculinized and fictive advertisement calling is degraded (Zornik and Yamaguchi, 2011). Androgens and estrogens thus strongly affect vocal performance in adults by acting on laryngeal muscle, the laryngeal neuromuscular synapse, and vocal CPG components.

Adult males have more muscle fibers overall, more fast-twitch laryngeal muscle fibers than females (Sassoon et al., 1987; Marin et al., 1990) and more vocal motor neurons that provide laryngeal innervation (Robertson et al., 1994). Sex differences in laryngeal muscle depend both on proliferation of stem cells and innerva- tion by vocal motor neurons during development. Laryngeal myogenesis is due to proliferation and fusion of satellite cells, a stem cell class (Sassoon et al., 1986; Yin et al., 2013). In juvenile $X$. laevis larynx, satellite cells express a specific androgen receptor isoform (Fischer et al., 1995) and a myosin heavy chain that is otherwise exclusively expressed in adult laryngeal muscle (Catz et al., 1992; Nasipak and Kelley, 2012). Satellite cells respond to exogenous androgen by proliferating in vivo (Sassoon et al., 1986) and in vitro (Nasipak and Kelley, 2012), and blocking satellite cell proliferation prevents androgen-induced fiber type switching. The greater number and entirely fast-twitch complement of laryngeal muscle fibers in males relative to females are thus both due to proliferation, fusion, and differentiation of these satellite cells. In contrast to sexually differentiated muscle fiber number and type, the greater number of vocal motor neurons in NA in males is due to reduction of ontogenetic cell death (Kay et al., 1999). As denervation reduces satellite cell number (Yin et al., 2013), and male laryngeal axon numbers are greater than female numbers by tadpole stage 47 (Robertson et al., 1994), laryngeal innervation could also contribute to the greater muscle fiber number in males.

\section{The vocal central pattern generator}

A hallmark of CPGs is that they can function in the absence of rhythmic sensory inputs from the periphery, often possessing the ability to produce in vivo neuronal patterns ex vivo. Central pattern generators are thus powerful systems for studying how neuronal circuits generate rhythmic motor programs (Marder and Bucher, 2001). The ex vivo Xenopus brain (Fig. 2B) is one such CPG system (Rhodes et al., 2007). Application of serotonin to the isolated male $X$. laevis brain evokes repeated bouts of patterned laryngeal nerve activity: compound action potentials (CAPs: Fig. 3 ) with durations ( $\sim 250 \mathrm{~ms}$ fast; $\sim 750 \mathrm{~ms}$ slow $)$ and rates $(\sim 60$ $\mathrm{Hz}$ fast; $\sim 30 \mathrm{~Hz}$ slow) corresponding to nerve activity during actual advertisement calls (Rhodes et al., 2007; Fig. 3B). Application of serotonin to the isolated female brain results in patterned 
nerve activity of variable durations that corresponds to actual female ticking (Fig. 1). These patterns recorded from the laryngeal nerve in the ex vivo brain are termed fictive calling. The ex vivo male brain also produces spontaneous fictive male amplectant calling, a call given by a clasping male (Fig. 1; Zornik and Kelley, 2008).

Serotonin continues to evoke fictive calling from the ex vivo male brain transected just posterior to the midbrain (Rhodes et al., 2007); the hindbrain thus contains neural components sufficient for generating the advertisement call. This result suggested that hindbrain neural components, specifically including androgen receptor expressing vocal motor neurons in posterior hindbrain (NA) and androgen receptor expressing neurons in anterior hindbrain, the parabrachial nucleus (formerly DTAM; Kelley, 1980; Zornik and Kelley, 2007, 2008) contribute to generating the advertisement call pattern. However, if connections between the parabrachial nuclei and nuclei ambiguus are cut bilaterally, fictive calling fails (Rhodes et al., 2007). The current model (Yamaguchi et al., 2017) is that the hindbrain CPG for advertisement calling includes NA in the posterior hindbrain, the parabrachial nucleus in the anterior hindbrain as well as a recurrent contribution originating from vocal motor neurons (Lawton et al., 2017; Barkan and Zornik, 2019; Fig. 2C).

Generating coordinated movements of both sides of the bodylocomotion, swimming, flying - requires bilateral coordination of CPGs (Kiehn, 2016). In some rhythmic motor programs, muscles must be activated in anti-phase (e.g., during walking), whereas other motor patterns require simultaneous bilateral activation (e.g., during hopping). In the Xenopus vocal system, vocal motor neurons project ipsilaterally to laryngeal muscle targets (Tobias and Kelley, 1987; Fig. 2C), whereas simultaneous contraction of left and right laryngeal muscles is required for sound production (Kwong-Brown et al., 2019). This coordination is accomplished by interneurons in anteromedial NA (amNA) that provide bilateral connections between left and right NA as well as reciprocal, ascending and descending, ipsilateral, and contralateral connections between the parabrachial nucleus and NA (Fig. 2C; Zornik and Kelley, 2007; Yamaguchi et al., 2017). Together these connections form an anterior hindbrain commissure between left and right parabrachial nuclei and a posterior hindbrain commissure between left and right NA (Fig. 2C). A sagittal midline cut through either the anterior commissure, the posterior commissure, or both, results in disruption of right-left synchronous activity in the parabrachial nucleus as well as compound action potentials recorded from the laryngeal nerves, but not the underlying fast-slow advertisement call pattern. The left and right sides of the hindbrain thus contain independent vocal CPGs. A unilateral, transverse cut between the parabrachial nucleus and NA disrupts fictive fast, but not slow, trill on the same side, indicating that slow and fast trill are generated by different CPGs (Yamaguchi et al., 2017).

A current challenge for understanding the mechanisms of CPG function (and more generally, all neuronal circuits), is identifying functional neuronal subtypes within a circuit. While identifying most, if not all, of the neurons involved in invertebrate circuits, such as the crustacean stomatogastric ganglion (Marder and Bucher, 2001) and nudibranch mollusk swimming CPGs (Katz, 2016), has been in place for decades, cell-type-specific understanding of vertebrate CPGs has lagged. The isolated Xenopus brain-like the frog, fish, and rodent spinal locomotor circuitsallows for straightforward electrophysiological investigations as fictive behaviors are generated. Local field potential (LFP) recordings from the parabrachial nucleus of males during fictive advertisement calls reveal a stereotyped LFP (Fig. 3B) corresponding to fast trill duration and period (Zornik et al., 2010). Localized cooling of the parabrachial nucleus reveals that it determines the fast trill rate and the overall call period (Zornik et al., 2010). These findings prompted the use of blind whole-cell patch-clamp recordings in the parabrachial nucleus (Zornik and Yamaguchi, 2012), which led to the identification of two populations of intrinsically rhythmic neurons that are active during fictive calling: fast trill neurons and early vocal neurons (Barkan et al., 2018). Fast trill neuron spikes (Zornik and Yamaguchi, 2012) but not early vocal neuron spikes (Barkan et al., 2018) precede each compound action potential in fictive fast trills. Fast trill neurons thus likely drive fast trill and correspond to the glutamatergic parabrachial neurons that form strong, excitatory, short-latency synapses on vocal motor neurons (Zornik and Kelley, 2008). The role of early vocal neurons is less clear. Because the parabrachial LFP is NMDA-dependent (Zornik and Yamaguchi, 2012), early vocal neurons might be excitatory, facilitating both fast trill initiation, via NMDA activation of fast trill neurons, and termination, because their activity usually stops before fast trill ends (Barkan et al., 2018). Alternatively, early vocal neurons might be inhibitory, possibly responsible for the inhibitory postsynaptic currents in parabrachial neurons that are phase-locked to compound action potentials recorded from the nerve (Zornik and Yamaguchi, 2012).

Whereas motor neurons in invertebrates are known to play key roles in pattern generation, in vertebrates they are more typically considered to be relays between the upstream neural circuitry and muscles (for review, see Barkan and Zornik, 2019). Recent evidence in the Xenopus vocal CPG, however, has identified a potential role for motor neurons in the production of vocal patterns. Neurons in the parabrachial nucleus receive inhibitory input shortly after each compound action potential recorded from the laryngeal nerve. These inhibitory postsynaptic potentials, and the precision of parabrachial neuron spiking require intact connections with NA (Lawton et al., 2017). When vocal motor neurons are pharmacologically inactivated or when cholinergic transmission in NA is blocked, parabrachial nucleus phasic activity is disrupted. These observations suggest that axon collaterals of vocal motor neurons release acetylcholine to excite inhibitory neurons that project to the parabrachial nucleus.

Despite evidence for vocal motor neuron-activation providing inhibitory feedback onto parabrachial premotor neurons, their precise cellular identities are not yet known. Where are these neurons located? Some neurons in anteromedial NA project to, and receive input from, the parabrachial nucleus as well as contralateral NA (Fig. 2C; Zornik and Kelley, 2007). Neurons immunoreactive for the inhibitory transmitter GABA have been identified in both parabrachial nucleus and NA (Hollis and Boyd, 2005). Possible inhibitory routes are (1) vocal motor neuron axon collaterals projecting anteriorly to parabrachial nucleus neurons and synapsing on inhibitory early vocal neurons or (2) vocal motor neuron axon collaterals synapsing on inhibitory interneurons within NA (Zornik and Kelley, 2007; Fig. 2C). Lucifer yellow fills of the laryngeal nerve did not reveal ascending vocal motor neuron collaterals (Simpson et al., 1986) so option 2 is more likely. In option 2, GABAergic interneurons in NA would project anteriorly and synapse on the fast trill neurons. In either case, results of vocal motor neuron inactivation show that motor neurons are part of the Xenopus vocal CPG as for other CPGs across taxa (Lawton et al., 2017; Barkan and Zornik, 2019).

Whole-cell electrophysiological recording during naturalistic vocal circuit activity, possible in the ex vivo brain preparation, has 

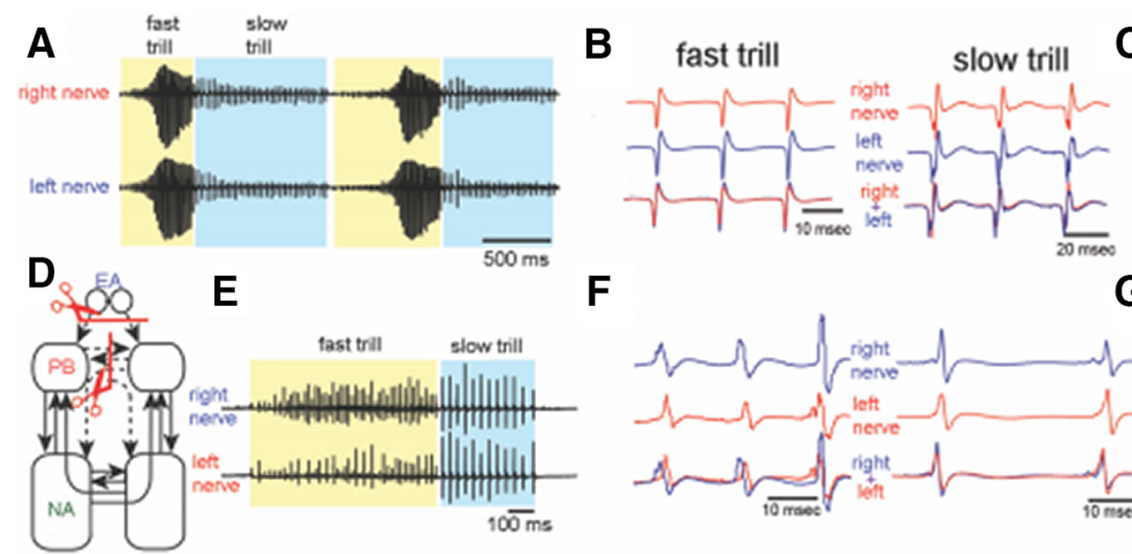

$\mathbf{F}$

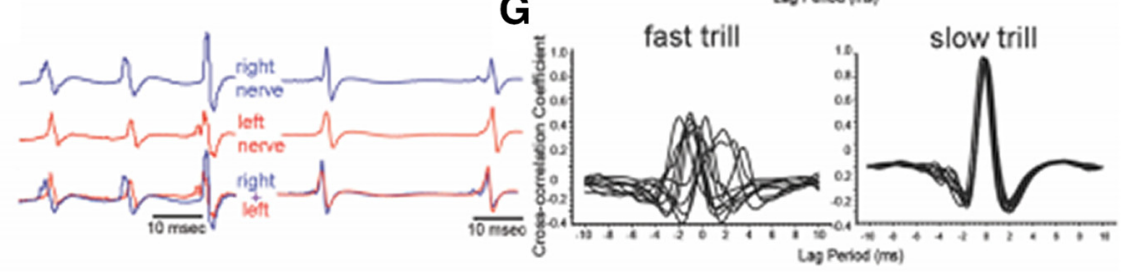

Figure 4. Transecting both the anterior commissure (Fig. 2C) and forebrain input (including the EA:CeA plus BNST) to PB disrupts synchrony of fictive fast but not slow trills. A, Recordings from the left and right laryngeal nerves in an intact male brain. $B$, Enlarged views of left (blue) and right (red) nerve recordings during fictive fast and slow trills; traces from left and right nerve overlap. C, Example cross-correlation between the left and right nerve during fictive fast and slow trills calculated by a sliding a recording of a single compound action potential from one nerve over the other. Peak cross-correlation coefficients are centered around zero, indicating that the two nerves are active simultaneously. $\boldsymbol{D}$, Bilateral forebrain and anterior commissure input to the PB were removed. Transection is indicated by a red line with scissors, transected projections by dotted arrows, and intact projections by solid arrows. $E$, Recordings from the left (top trace) and right (bottom trace) laryngeal nerves in an intact male brain. $F$, Enlarged views of left (red) and right (blue) nerve recordings during fictive fast and slow trills in a transected brain. The bottom trace shows the overlay of the left and right nerve recordings. G, A cross-correlation between the left and right nerve during fast and slow trills generated by a double-transected brain. The peak cross-correlation coefficient for slow trills is centered around zero, as in the intact brain, but for fast trills correlation coefficients are variable, indicating that the left and right laryngeal nerves are activated simultaneously during slow trills, but asynchronously during fast trills. Modified from Yamaguchi et al. (2017).

allowed the identification of functional neuronal subtypes in the vocal CPG and is beginning to reveal connectivity. The Xenopus vocal CPG represents one of a few vertebrate hindbrain CPGs currently under investigation, including CPGs for mammalian respiration (Del Negro et al., 2018), plainfin midshipman vocalizations (Feng and Bass, 2016), and signaling of weakly electric fish (Quintana et al., 2011). Together these will establish a framework for understanding the cellular and network properties of hindbrain circuitry across species and behaviors.

\section{The forebrain and call initiation}

As noted above, in the ex vivo calling brain, serotonin (5-HT) plays a crucial role in initiating vocalization. Exogenous application to the ex vivo male brain promotes fictive advertisement calling (Rhodes et al., 2007), as does elevating endogenous serotonin levels using a selective serotonin reuptake inhibitor ( $\mathrm{Yu}$ and Yamaguchi, 2010). Endogenous serotonin thus contributes to call initiation.

$5-\mathrm{HT}_{2 \mathrm{C}}$ receptors are necessary for serotonin-induced fictive advertisement calling (Yu and Yamaguchi, 2010), but where does receptor activation occur? The hindbrain contains two groups of $5-\mathrm{HT}_{2 \mathrm{C}}$ receptor-expressing cells: one in amNA (Fig. $2 \mathrm{C}$, green) and another in the raphe nucleus (Fig. $2 C$, purple). One or both of these targets within the intact hindbrain are sufficient for serotonin to evoke synchronized fictive advertisement calls. Exogenous application of 5- $\mathrm{HT}_{2 \mathrm{C}}$ agonists to the hindbrain, isolated from the rest of the ex vivo brain, also initiates fictive calling (Yu and Yamaguchi, 2010).

Actual calling requires precise synchronization of left and right vocal CPGs so that left and right laryngeal muscles can contract synchronously and separate the arytenoid discs at the velocity required to generate a sound pulse (Kwong-Brown et al., 2019). When the ex vivo brain was transected anterior to the midbrain, removing all descending forebrain input, and the anterior commissure connecting left and right parabrachial nuclei was transected (Fig. $2 B$, white lines, ${ }^{\star}$ and ${ }^{\star \star}$, respectively), fictive fast, but not slow, trills were initiated asynchronously (Yamaguchi et al., 2017; Fig. 4). However, either transection alone maintained synchronous initiation (data not shown) suggesting that multiple mechanisms for coordination of the vocal CPG are present in both forebrain and hindbrain.

Fast trill synchrony could be facilitated by the forebrain extended amygdala [EA; central nucleus of the amygdala (CeA), plus bed nucleus of the stria terminalis (BNST); Fig. 2C] because electrical microstimulation of these areas in ex vivo brains results in initiation without application of exogenous serotonin (Hall et al., 2013). The central amygdala projects directly to the parabrachial nucleus and the bed nucleus of the stria terminalis projects to the raphe (Brahic and Kelley, 2003; Moreno et al., 2012; Hall et al., 2013), one of two hindbrain nuclei that express the 5-HT2 c receptors required for fictive calling. While the central amygdala projects to the bed nucleus of the stria terminalis, the BNST does not project to CeA. Thus either CeA or BNST, or both, might contribute to synchronous initiation of fast trill via the midline raphe nucleus (Fig. 2C). In vivo lesions of the bed nucleus of the stria terminalis markedly decrease hCG-promoted spontaneous calling, but not calling while with an actual female (Hall et al., 2013). This result suggests that BNST input to the raphe is sufficient to initiate spontaneous advertisement calling, whereas the central amygdala is required for socially-evoked vocal responses. A potential role for the CeA in conveying social context-specific auditory information is described in the following sections.

\section{Auditory input to the vocal CPG}

In X. laevis, calls can be evoked and modified by acoustic and other sensory signals in both sexes (Fig. 1). How does auditory input access neural elements that in turn generate an appropriate vocal response; how is perception linked to production?

The Xenopus ear adapted to its aquatic habitat. Sounds are transduced via a tympanic disk just underneath the skin of the head (Christensen-Dalsgaard and Elepfandt, 1995). Fibers of the eighth cranial nerve (N. VIII), originating in the auditory ganglion, innervate the amphibian and basilar papillae of the inner ear peripherally (Elliott et al., 2007; Mason et al., 2009). Axons from the ganglion extend centrally to enter the hindbrain and terminate in the dorsal medullary nucleus. Although both males and females are most acoustically sensitive to the dominant fre- 


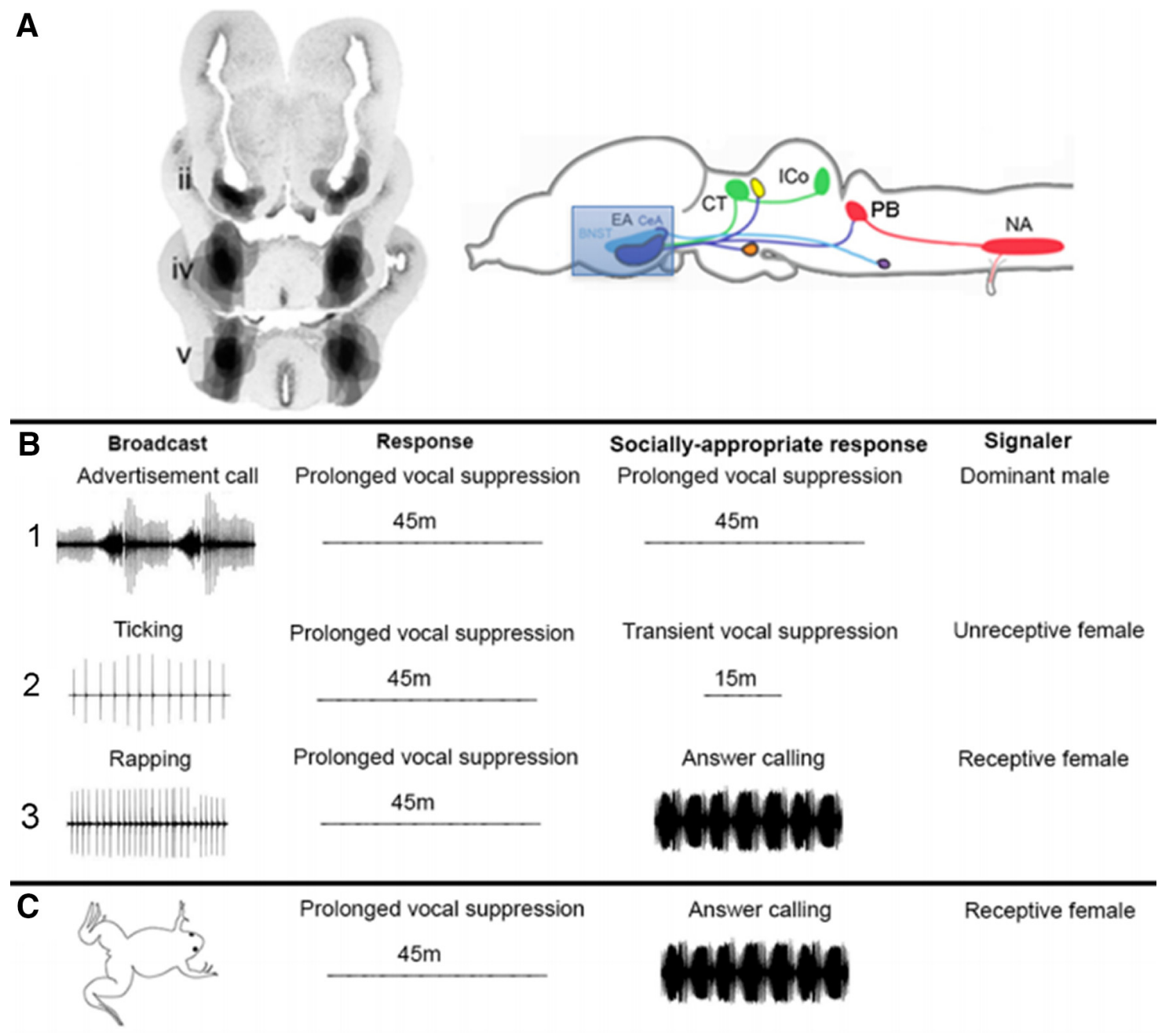

Figure 5. Damage to the CeA of males results in socially inappropriate responses to female calls. Effects of different calls were assessed in males with lesions of the EA (CeA and BNST). Males called spontaneously after CeA lesions so were not mute. $A$, Lesions of the EA are shown in transverse sections through the forebrain (Hall et al., 2013) and schematically in a sagittal view. Auditory nuclei in green, components of the vocal CPG in red. B1, Lesioned males responded to broadcasts of male advertisement calls with prolonged vocal suppression, the socially appropriate response, so lesioned males were not deaf. $\mathbf{B 2}$, Lesioned males respond to ticking with prolonged rather than socially-appropriate transient vocal suppression. $\boldsymbol{B}$, Lesioned males responded to broadcasts of rapping with prolonged vocal suppression rather than answer calling. C, Even when paired with a rapping, receptive female, CeA-lesioned males exhibit prolonged vocal suppression.

quencies of the male advertisement call, across Xenopus species, peripheral (auditory ganglion) sensitivity is greater in females than in males (Hall et al., 2016). In X. laevis, this sex difference was abolished by ovariectomy and reinstated by androgen, the major circulating gonadal steroid in females (Lutz et al., 2001), indicating endocrine regulation of peripheral auditory sensitivity in females, perhaps because of androgen receptor expression in auditory ganglion neurons (Pérez et al., 1996).

The dorsal medullary nucleus projects to the auditory midbrain, the laminar nucleus of the inferior colliculus (ICo), directly and via the superior olive (Paton et al., 1982; Edwards and Kelley, 2001). Neurons in the ICo express estrogen and androgen receptors (Morrell et al., 1975), are activated by sound (Kelley, 1980; Paton et al., 1982), and are temporally selective for callspecific sound pulse rates (Elliott et al., 2011). ICo in turn projects, via the posterocentral nucleus of the thalamus, to the CeA (Hall et al., 2013). CeA projects to the parabrachial nucleus directly but also via the bed nucleus of the stria terminalis (Moreno and González, 2005; Moreno et al., 2012; Hall et al., 2013), providing an additional route for auditory information to influence the vocal CPG via BNST-stimulated, serotonergic input from the raphe nucleus (Fig. 2C). Neurons in the central nucleus of the amygdala express gonadotropin and estrogen receptors (Morrell et al., 1975; Yang et al., 2007). Thus, both for sensory and motor systems, $X$. laevis neurons that participate in vocal communication express the receptors that confer direct sensitivity to highly conserved hormones essential for vertebrate reproduction.

Males respond to female rapping by increasing advertisement calling and initiating answer calling (Tobias et al., 1998a). The central nucleus of the amygdala is a strong candidate for a role in auditory-guided, endocrine-responsive, vocal communication. We lesioned the CeA bilaterally in males (Fig. 5A) and analyzed their vocal responses to male and female calls (Fig. $5 B, C$; Hall et al., 2013, their data). Lesioned males call spontaneously (data not shown) so they are not mute. They also respond to advertisement calls with prolonged vocal suppression (Fig. 5B1), so they are not deaf and can produce the socially appropriate response to a dominant male. However, while ticking normally evokes transient vocal suppression in males (Elliott and Kelley, 2007), CeA-lesioned males respond with prolonged vocal suppression (Fig. 5B2). Rapping evokes answer calling in intact males (Tobias et al., 1998a) but CeA-lesioned males respond to rapping with prolonged vocal suppression (Fig. 5B3). Prolonged vocal suppression should only 
A

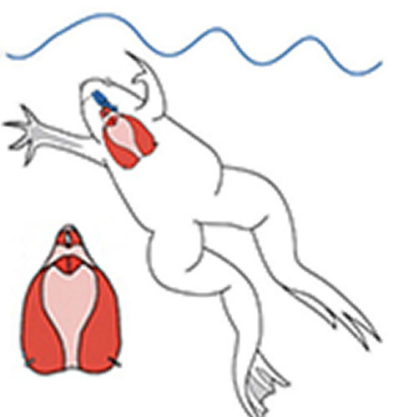

B

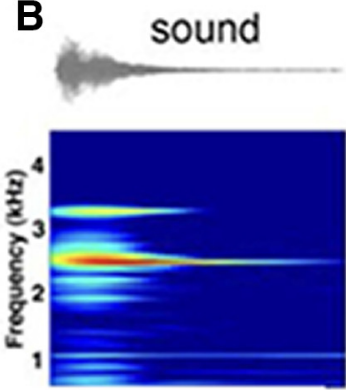

D

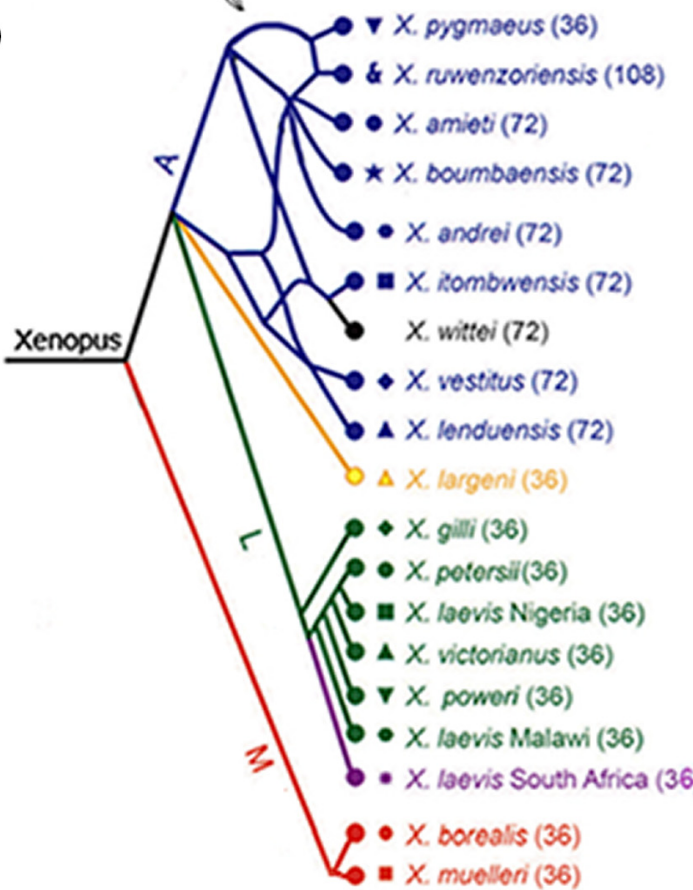

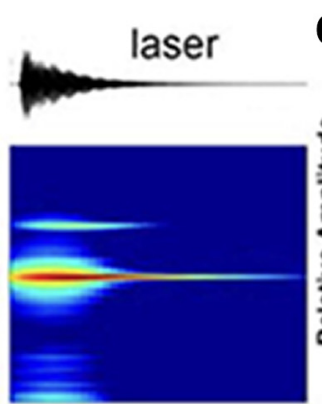

C
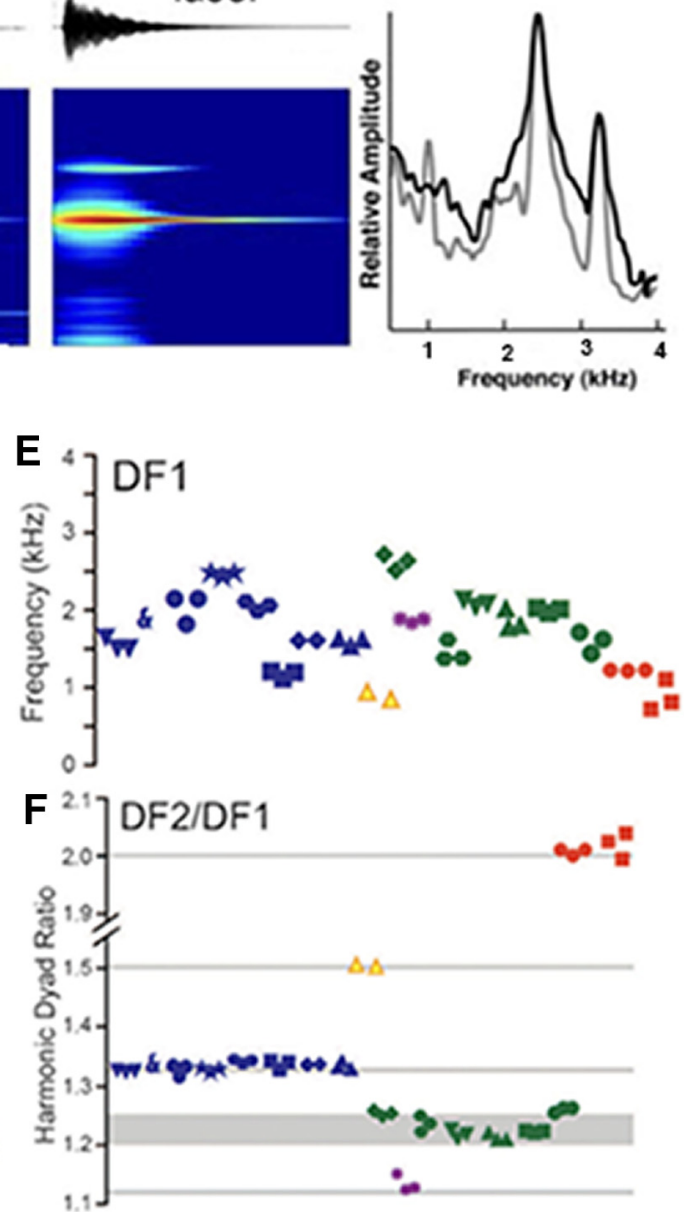

Figure 6. A, Advertisement calls were recorded underwater from vocalizing males or from the exvivolarynx, at left. Note the relative sizes of the brain (blue) and larynx (red). $\boldsymbol{B}$, A single sound pulse. Acoustic (gray) or laser inferometry (black) recordings reveal two dominant frequencies (O. D, Phylogenetic representation of species and populations from which advertisement calls were recorded, color-coded by clade ( $\mathrm{A}$, blue; $\mathrm{L}$, green and purple; $\mathrm{M}$, red and black). Ploidy levels for each species are in parentheses: $36=$ tetraploid. Symbols correspond to individuals of each species in $\boldsymbol{E}$ and $\boldsymbol{F}$. Updated according to Evans et al. (2019) for $X$. fraseri. $E$, Although both the lower DF1 and higher (data not shown) DF2 overlap across species, their ratios ( $\boldsymbol{F}$ ) are species-group. DF2-DF1 ratios and their harmonic intervals: 2.0 (octave), 1.5 (perfect 5th), 1.34 (perfect 4th), and 1.22,(minor 3rd), 1.25 (major 3rd). For X. itombuensis audio recording, see Movie 1. Modified from Kwong-Brown et al. (2019).

be evoked by the calls of dominant males (Fig. 5B1:Tobias et al., 2004), not by ticking or rapping. Even when tested with an actual rapping female (Fig. 5C), males do not answer call. Damage to the CeA thus results in socially inappropriate responses of males to female, but not to male, calls.

\section{Evolution of vocal communication}

Across taxa, vocal communication systems evolve with speciation (Mason et al., 2017; Xu and Shaw, 2019). Because other hominin groups, Neanderthals for example, did not survive for comparison, it has been particularly difficult to determine how human language, as a form of vocal communication, evolved in Homo sapiens. A role for primate vocalizations in social cognition could be one factor (Seyfarth and Cheney, 2008). For the neural circuitry underlying language in $H$. sapiens we are generally limited to brain imaging or recording from individual candidate speech areas before or during neurosurgery (Mesgarani et al., 2014). Basic principles of how vocal circuits and production diverge across evolution and function in social communication can emerge from comparisons of species-rich genera, such as Xenopus, in which auditory and vocal circuits and social interactions can be studied in detail using multidisciplinary approaches.

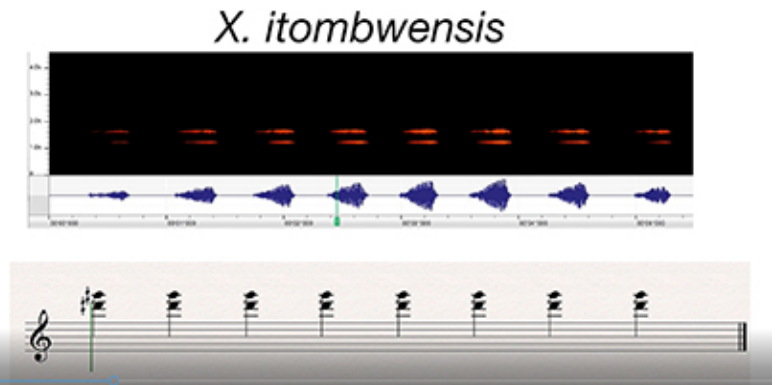

Movie 1. This video provides an acoustic template for hearing the perfect fourth in the $X$. itombuensis DF2-DF1 ratio.

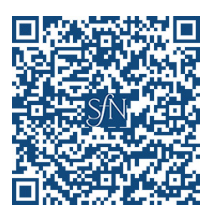

Temporal features: divergent evolution

The L-group species (Fig. 6, green) X. laevis and X. petersii, diverged $\sim 8.5$ mya (Furman et al., 2015). Both are biphasic callers with slow (30 pps) and fast (60 pps) trills that alternate (Tobias et 
A

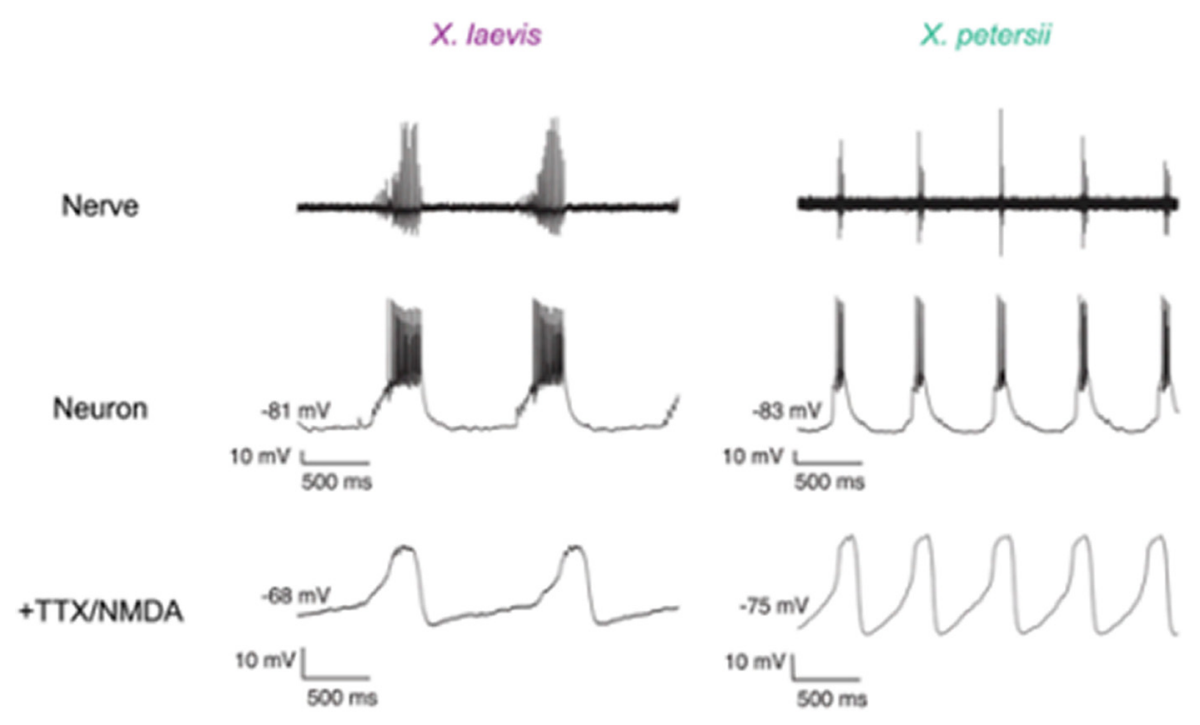

D

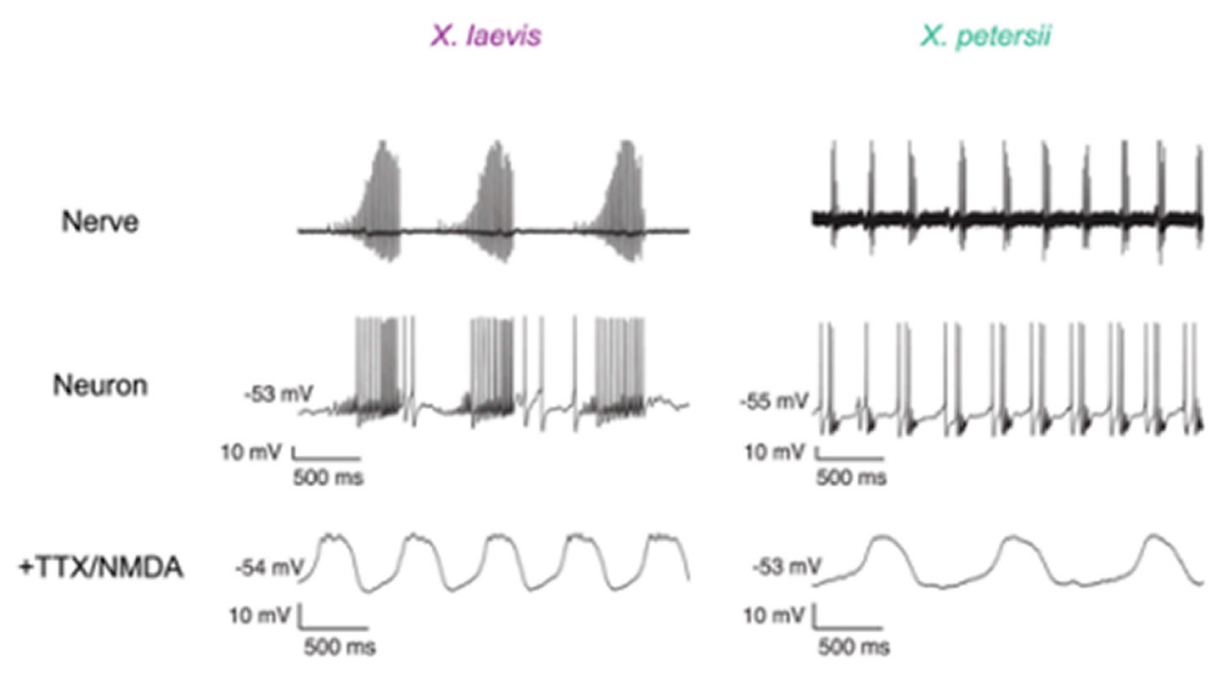

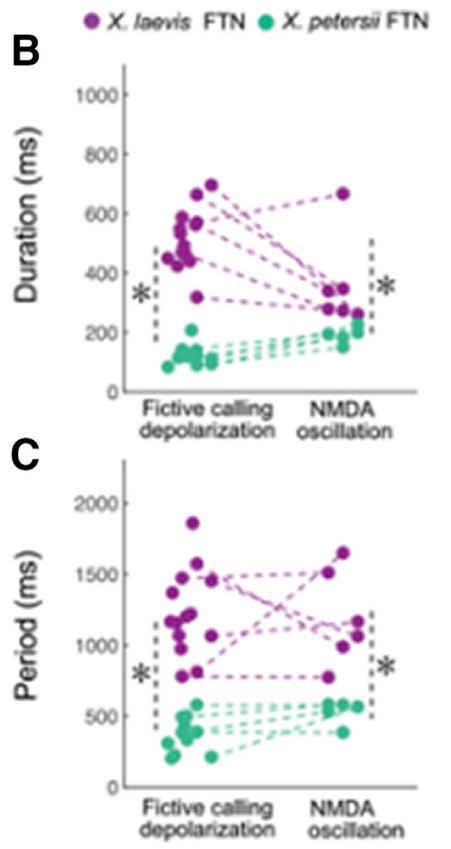

E $\quad \Delta X$ laevis EVN $\Delta X$ petersil EVN
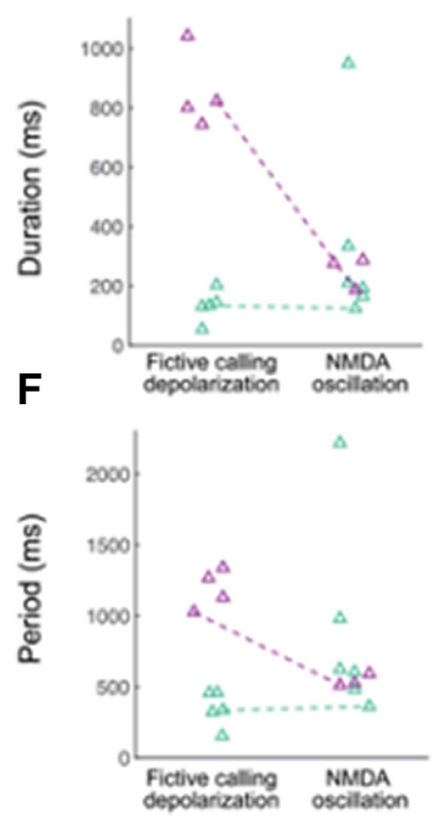

Figure 7. The PB includes two classes of intrinsically, rhythmic neurons: early vocal neurons (EVNs) and fast trill neurons (FTNs). $A, D$, Laryngeal nerve and intracellular recordings in PB from $X$. laevis and X. petersii. The duration and period of FTN neuron depolarization and NMDA-induced oscillation $(\boldsymbol{B}, \boldsymbol{C})$, but not EVN neuron depolarization and membrane oscillation $(\boldsymbol{E}, \boldsymbol{F})$, match species-specific temporal features of calls. Asterisks indicated significant differences between species. Reproduced from Barkan et al. (2018).

al., 2011). Studies in the exvivo brain reveal that the duration and period of parabrachial nucleus activity matches the duration of fast trill in both $X$. petersii and X. laevis, and thus is longer in $X$. laevis (Barkan et al., 2017). Intracellular recordings of neurons in the $X$. laevis parabrachial nucleus during fictive calling uncovered two classes of neurons: fast trill neurons and early vocal neurons. These two cell types are also present in X. petersii parabrachial nucleus (PB; Barkan et al., 2018; Fig. 7). Current injection into fast trill neurons but not early vocal neurons revealed species differences in spike burst durations but not in membrane resistance and resting membrane potential (among other intrinsic properties). When fast trill neurons, but not early vocal neu- rons, are synaptically isolated and exposed to NMDA, membrane voltages oscillate with period and duration corresponding to species-specific calls (Fig. 7). Fast trill neuron membrane currents, probably involving distinct expression of ion channels, are strong candidates for vocal divergence. To date, very few studies have identified relations between differences in membrane currents and behavior. In weakly electric fish, androgens and estrogens appear to act directly on electrocyte (modified muscle cells) sodium currents that generate sex-specific electric organ discharges (Ferrari et al., 1995; Dunlap et al., 1997). In one of the best studied CPGs, the crab stomatogastric ganglion, differences in expression of a potassium channel gene required for generat- 
ing the transient potassium current, $I_{A}$, were strongly correlated with behavioral period (Goaillard et al., 2009). Determining which membrane proteins contribute to differences in $X$. laevis and $X$. petersii parabrachial neurons will afford insight into cellular mechanisms underlying behavioral evolution.

\section{Temporal features:}

convergent evolution

Male advertisement call temporal patterns in Xenopus can be characterized as one of four types: click, burst, trill, and biphasic. Parsimony analysis suggests that the burst-type pattern was ancestral (Tobias et al., 2011). Across the genus (Fig. $6 D)$, the single click-type is the rarest call, appearing once in the A-group and twice in the M-group. Comparison of representative species (X. boumbaensis, A, and $X$. borealis, $M$ ) evolved convergently through different neural, neuromuscular and muscle mechanisms (Leininger and Kelley, 2013; Leininger et al., 2015). X. boumbaensis brains generate a fictive burst pattern $(\sim 0.83$ bursts/s $)$ of two tightly coordinated compound action potentials. All male $X$. boumbaensis laryngeal muscle fibers are fast twitch and female fibers are mostly slow twitch, meaning that in principle, X. boumbaensis males could produce rapid sound pulse trains similar to $X$. laevis vocalizations. Burst stimuli delivered to the larynx via the laryngeal nerve produce a highly potentiated laryngeal electromyogram, a single muscle contraction and a single sound pulse (Leininger and Kelley, 2013), indicating that the neuromuscular synapse requires facilitation for sound pulse production as in male X. laevis (Ruel et al., 1997). However, because the output of the central pattern generator is a short burst of just two compound action potentials, the resulting vocalization is a single sound pulse rather than a train of pulses with increasing intensity. In $X$. boumbaensis, then, a temporally simplified vocal pattern reflects a shorter CPG output period whose basis is not yet identified.

In contrast, $X$. borealis brains generate a vocal pattern faithful to the in vivo call (2.2 pps; Tobias et al., 2011). Single stimuli delivered to the laryngeal nerve are sufficient for single muscle contractions (Leininger and Kelley, 2013), suggesting that the neuromuscular synapse is strong, as in female $X$. laevis (Tobias et al., 1995). How the vocal CPG produces the 2.2 pps pattern in males has not been determined. $X$. borealis laryngeal muscle is sexually dimorphic in mass and muscle fiber number but contains a mixture of fast and slow twitch fibers in both sexes, a trait thus far unique in those Xenopus species for which muscle physiology has been characterized (Leininger et al., 2015). Because laryngeal muscle fiber type is regulated by gonadal androgen in X. laevis (Sassoon et al., 1987) and X. tropicalis (Baur et al., 2008) the selective loss of masculinized laryngeal muscle fiber type in $X$. borealis might be due to evolutionary loss of a portion of the program for peripheral, androgen-driven sexual differentiation. In any case, the shared click-type calls of X. borealis and X. boumbaensis are due to evolutionary convergence of vocal phenotype produced by divergent neural and muscular mechanisms.

\section{Spectral features-divergent evolution}

Although call patterns are determined by the vocal CPG, the laryngeal synapse, and muscle fiber type, the spectral qualities of these calls are determined by intrinsic properties of the larynx (Tobias and Kelley, 1987; Yager, 1992; Kwong-Brown et al., 2019). Stimulating the laryngeal nerves of ex vivo male larynges results in sound pulses containing species-typical dominant frequencies [illustrated for the lower dominant frequency (DF1): Fig. 5E. KwongBrown et al., 2019]. With one exception (X. fischbergii, Evans et al., 2019; each sound pulse is an harmonic stack), pulses in male advertisement calls from groups $\mathrm{A}, \mathrm{L}$, and $\mathrm{M}$ contain two simultaneous dominant frequencies (Fig. $5 B, C$ ) and it is these dyads, together with call temporal patterns, that are unique for each species (Tobias et al., 2011). Although dominant frequencies overlap across species (Fig. $5 E$, DF1), their ratios (Fig. $5 F$ ) are species-group-specific. These harmonic ratios can be identified acoustically as intervals in the Western musical scale: octaves, perfect fourths (Movie 1), major and minor thirds, a perfect fifth.

Dyads are a complex mode of laryngeal vibration set into motion by rapid separation of the arytenoid discs, encapsulated in elastic cartilage and transmitted throughout the larynx via elastic cartilage seams (Kwong-Brown et al., 2019). The larynx also includes a central lumen and two side chambers separated by sheets of elastic cartilage. Puncturing these sheets disrupted the DFs, whereas several other manipulations, such as replacing air with helium, did not. Intact partitioning by elastic cartilage is essential for DF1, DF2, and dyad ratios. Although we do not know which shared laryngeal components, reflecting descent from a common ancestor, account for the dyad ratios, the DF2-DF1 ratio is remarkably conserved within each species group and serves as an acoustic signature for genetic similarity.

\section{A genetic architecture for vocal communication}

Temporal and spectral differences in Xenopus vocalizations across species are innate or genetically determined, rather than learned 
(Tobias et al., 2011, 2014). Examples of species differences are the divergence of membrane oscillations in fast trill neurons from $X$. laevis and X. petersii described by Barkan et al. (2018) and the greater auditory sensitivity of female Xenopus to dyads composed of their own species-specific frequencies at group-specific ratios (Hall et al., 2016). Species differences should be reflected in the neural circuitry, from the auditory periphery to the larynx, and be expressed by both the signaler and the responder. Heritable species differences in function of the vocal CPG, the larynx as well as auditory neurons suggest to us that the genetic architecture supports the neural architecture. One ongoing approach to assessing species divergence and convergence involves looking for differences in gene expression in specific vocal or auditory components, such as the fast trill neurons of the parabrachial nucleus or neurons of the auditory ganglion.

However, that genes contributing to call differences are evolving in historically diverging backgrounds, an unbiased genetic mapping approach (quantitative trait loci) would also be informative, as it has for other social behaviors such as parental behaviors in rodents (Bendesky et al., 2017) and insect songs (Ding et al., 2016; Xu and Shaw, 2019). Reference genomes from two species are obtained. Variation in maternally and paternally-derived species' vocal traits are quantified for large numbers of secondgeneration hybrid (F2) progeny and the association between genomic loci and quantitative traits analyzed statistically.

$X$. laevis and $X$. petersii advertisement calls differ spectrally (Fig. 6) and temporally (Fig. 7). Male X. laevis are the exception to the L-group-specific DF2-DF1 ratio (1.14 instead of 1.22; Tobias et al., 2011) and thus especially suitable for hybridizing with $X$. petersii because both spectral and temporal call features should vary. Both male and female progeny of crosses between species in the L-group species group are interfertile. Preliminary results from vocal phenotyping F1 hybrid $X$. laevis $\times X$. petersii males reveal spectral and temporal features that are intermediate to the pure parental species. F1 female hybrids appear more sensitive to spectral features of $\mathrm{F} 1$ hybrid calls than to the parental species (Perez et al., 2018). F2 offspring from crosses of specific F1 X. laevis $\times X$. petersii parents are being behaviorally phenotyped for linkage with each individual F2 male's genotype using a published $X$. laevis reference genome (Session et al., 2016) and a sequencing data from male $X$. petersii (T. Mitros, R. Harland: UC Berkeley).

\section{Challenges: vertebrate vocal circuitry}

In X. laevis we have learned that advertisement call vocal patterns are generated by a CPG distributed between the anterior and posterior hindbrain (parabrachial nucleus and NA). Left and right CPGs are independent but coordinated by an extensive network of commissural and bilateral interneuron projections between anterior and posterior nuclei; descending input from the forebrain nuclei (the extended amygdala: CeA and BNST) serves to coordinate simultaneous initiation of advertisement calling. Damage to the CeA results in socially inappropriate vocal responses of males to female calls.

However, while the fast trill portion is generated by neurons in the parabrachial nucleus, the source of the slow trill pattern remains to be identified. The temporal precision of fast trill neuron spikes depends on intact feedback from vocal motor neurons to the parabrachial nucleus (Lawton et al., 2017). This feedback is cholinergic and presumably excitatory; however, it is inhibitory input that shapes the temporal precision of $\mathrm{PB}$ phasic activity. The central amygdala is almost entirely GABAergic (Moreno et al., 2012) and should be inhibitory. However microstimulation excites fictive calling in males (Hall et al., 2013), implying that CeA output inhibits a source of, as yet unidentified, inhibitory input to the vocal CPG. The identity and location of these inhibitory neurons is not known but molecular markers of neuronal identity may be helpful (Sweeney and Kelley, 2014) as has been the case for hindbrain respiratory CPGs (Baertsch et al., 2018). Viral tracing methods in Xenopus (Fig. 8; Yamaguchi et al., 2018) should facilitate the analysis of this entire social communication circuit at mesoscale (Mitra, 2014).

The advertisement call is only one of six call types (Fig. 1) produced by males. What circuits generate slow trill, the other five call types in males as well as ticking and rapping in females? Advertisement calling in males is androgen- and gonadotropindependent and components of the underlying neural circuitry express hormone receptors. The vocal CPG of females can be masculinized by androgen treatment, which also masculinizes female calling behavior (Rhodes et al., 2007). How androgen reconfigures the vocal CPG in females to produce male-like vocal patterns is not known. Exactly how estrogen strengthens laryngeal muscle synapses is also unknown as is the role of gonadotropins in CeA.

What differences in gene expression support divergent vocal patterns within each species group? For convergent patterns, how has the Xenopus vocal CPG, which is known to contain speciesspecific fast-trill neurons in some species, been reconfigured to generate a much simpler output that lacks a fast trill in X. borealis and $X$. boumbaensis? How have conserved masculinized features of the vocal circuit been selectively lost in species with reduced vocal sex differences? More broadly, which aspects of the vocal CPG in Xenopus are specific to its evolutionary history and which are shared across vertebrates?

The basic circuitry for generating different, larynx-based vocal patterns is likely to reside in the hindbrain where motor neurons are located (Albersheim-Carter et al., 2016). The larynx and the syrinx of birds are interposed between the mouth and the lungs; air flow drives sound production and respiration must thus be linked to vocalization (Fitch and Suthers, 2016). The parabrachial nucleus serves this role in bats (Smotherman et al., 2006). In cats, parabrachial nucleus activity is rhythmic and linked to inspiration (Dick et al., 1994). In lampreys, basal vertebrates that do not vocalize, a rhythmically active anterior hindbrain nucleus (the pTRG) that projects to NA motor neurons drives fast inspiration (Cinelli et al., 2013) and is a likely parabrachial homolog. A second component of the lamprey respiratory CPG drives slow inspiration and is found in anterior NA (Missaghi et al., 2016) where the mammalian pre-inspiratory complex is located (Baertsch et al., 2018) and where midline transections abolish inspiration (Onimaru et al., 2015). Thus the Xenopus slow trill vocal CPG might also be found in anterior NA. If so, the anuran vocal CPG could be derived from more ancient respiratory circuits and be made up of deeply homologous components that generate breathing rhythms across vertebrates (Barkan et al., 2018). As our understanding of mammalian respiratory neural circuit components is rapidly advancing (Del Negro et al., 2018), this information could provide additional candidates for vocal CPG components in Xenopus. Pursuing these conserved links should provide new insights into brain evolution as well as road maps for understanding how neural circuits for social communication evolve.

\section{References}

Albersheim-Carter J, Blubaum A, Ballagh IH, Missaghi K, Siuda ER, McMurray $\mathrm{G}$, Bass $\mathrm{AH}$, Dubuc R, Kelley DB, Schmidt MF, Wilson RJ, Gray PA (2016) Testing the evolutionary conservation of vocal motoneurons in vertebrates. Respir Physiol Neurobiol 224:2-10. 
Baertsch NA, Baertsch HC, Ramirez JM (2018) The interdependence of excitation and inhibition for the control of dynamic breathing rhythms. Nat Commun 9:843.

Barkan CL, Zornik E (2019) Feedback to the future: motor neuron contributions to central pattern generator function. J Exp Biol 222:jeb193318.

Barkan CL, Zornik E, Kelley DB (2017) Evolution of vocal patterns: tuning hindbrain circuits during species divergence. J Exp Biol 220:856-867.

Barkan CL, Kelley DB, Zornik E (2018) Premotor neuron divergence reflects vocal evolution. J Neurosci 38:5325-5337.

Bass AH, Gilland EH, Baker R (2008) Evolutionary origins for social vocalization in a vertebrate hindbrain-spinal compartment. Science 321:417-421.

Baur L, Nasipak, BT, Kelley DB (2008) Sexually differentiated, androgenregulated, larynx-specific myosin heavy chain isoforms in Xenopus tropicalis and Xenopus laevis. Development, Genes and Evolution 218: 371-179.

Bendesky A, Kwon YM, Lassance JM, Lewarch CL, Yao S, Peterson BK, He MX, Dulac C, Hoekstra HE (2017) The genetic basis of parental care evolution in monogamous mice. Nature 544:434-439.

Billeter JC, Rideout EJ, Dornan AJ, Goodwin SF (2006) Control of male sexual behavior in Drosophila by the sex determination pathway. Curr Biol 16:R766-R776.

Bopp D, Saccone G, Beye, M (2014) Sex determination in insects: variations on a common theme. Sexual Development 8:20-28.

Brahic CJ, Kelley DB (2003) Vocal circuitry in Xenopus laevis: telencephalon to laryngeal motor neurons. J Comp Neurol 464:115-130.

Cannatella D (2015) Xenopusin space and time: fossils, node calibrations, tip-dating, and paleobiogeography. Cytogenet Genome Res 145:283-301.

Catz DS, Fischer LM, Moschella MC, Tobias ML, Kelley DB (1992) Sexually dimorphic expression of a laryngeal-specific, androgen-regulated myosin heavy chain gene during Xenopus laevis development. Dev Biol 154:366-376.

Christensen-Dalsgaard J, Elepfandt A (1995) Biophysics of underwater hearing in the clawed frog, Xenopus laevis. J Comp Physiol A 176:317-324.

Cinelli E, Robertson B, Mutolo D, Grillner S, Pantaleo T, Bongianni F (2013) Neuronal mechanisms of respiratory pattern generation are evolutionary conserved. J Neurosci 33:9104-9112.

Darwin C (1872) The descent of man, and selection in relation to sex, Vol. 2. Cambridge, UK: Cambridge UP.

Del Negro CA, Funk GD, Feldman JL (2018) Breathing matters. Nat Rev Neurosci 19:351-367.

Dick TE, Bellingham MC, Richter DW (1994) Pontine respiratory neurons in anesthetized cats. Brain Res 636:259-269.

Ding Y, Berrocal A, Morita T, Longden KD, Stern DL (2016) Natural courtship song variation caused by an intronic retroelement in an ion channel gene. Nature 536:329-332.

Dunlap KD, McAnelly ML, Zakon HH (1997) Estrogen modifies an electrocommunication signal by altering the electrocyte sodium current in an electric fish, Sternopygus. J Neurosci 17:2869-2875.

Edwards CJ, Kelley DB (2001) Auditory and lateral line inputs to the midbrain of an aquatic anuran: neuroanatomic studies in Xenopus laevis. J Comp Neurol 438:148-162.

Elemans CP, Rasmussen JH, Herbst CT, Düring DN, Zollinger SA, Brumm H, Srivastava K, Svane N, Ding M, Larsen ON, Sober SJ, Švec JG (2015) Universal mechanisms of sound production and control in birds and mammals. Nat Commun 6:8978.

Elliott TM, Kelley DB (2007) Male discrimination of receptive and unreceptive female calls by temporal features. J Exp Biol 210:2836-2842.

Elliott TM, Christensen-Dalsgaard J, Kelley DB (2007) Tone and call responses of units in the auditory nerve and dorsal medullary nucleus of Xenopus laevis. J Comp Physiol A Neuroethol Sens Neural Behav Physiol 193:1243-1257.

Elliott TM, Christensen-Dalsgaard J, Kelley DB (2011) Temporally selective processing of communication signals by auditory midbrain neurons. J Neurophysiol 105:1620-1632.

Evans BJ, Kelley DB, Melnick DJ, Cannatella DC (2005) Evolution of RAG-1 in polyploid clawed frogs. Mol Biol Evol 22:1193-1207.

Evans BJ, Greenbaum E, Kusamba C, Carter TF, Tobias ML, Mendel SA, Kelley DB (2011) Description of a new octoploid frog species (anura: pipidae: Xenopus) from the Democratic Republic of the Congo, with a discussion of the biogeography of African clawed frogs in the Albertine rift. J Zool 283:276-290.

Evans BJ, Carter TF, Greenbaum E, Gvoždík V, Kelley DB, McLaughlin PJ, Pauwels OS, Portik DM, Stanley EL, Tinsley RC, Tobias ML, Blackburn
DC (2015) Genetics, morphology, advertisement calls, and historical records distinguish six new polyploid species of african clawed frog (Xenopus, Pipidae) from West and Central Africa. PLoS One 10:e0142823.

Evans BJ, Gansauge MT, Stanley EL, Furman BL, Cauret CM, Ofori-Boateng C, Gvoždík V, Streicher JW, Greenbaum E, Tinsley RC, Meyer M, Blackburn DC (2019) Xenopus fraseri: Mr. Fraser, where did your frog come from? PLoS One 14:e0220892.

Feng NY, Bass AH (2016) "Singing" fish rely on circadian rhythm and melatonin for the timing of nocturnal courtship vocalization. Curr Biol 26:2681-2689.

Feng YJ, Blackburn DC, Liang D, Hillis DM, Wake DB, Cannatella DC, Zhang P (2017) Phylogenomics reveals rapid, simultaneous diversification of three major clades of Gondwanan frogs at the Cretaceous-Paleogene boundary. Proc Natl Acad Sci U S A 114:E5864-E5870.

Ferrari MB, McAnelly ML, Zakon HH (1995) Individual variation in and androgen-modulation of the sodium current in electric organ. J Neurosci 15:4023-4032.

Fine ML, Parmentier E (2015) Mechanisms of fish sound production. In: Sound communication in fishes, pp 77-126. Vienna: Springer.

Fischer LM, Catz D, Kelley DB (1995) Androgen-directed development of the Xenopus laevis larynx: control of androgen receptor expression and tissue differentiation. Dev Biol 170:115-126.

Fitch WT, Suthers RA (2016) Vertebrate vocal production: an introductory overview. In: Vertebrate sound production and acoustic communication, pp 1-18. Cham: Springer.

Franklin TB, Silva BA, Perova Z, Marrone L, Masferrer ME, Zhan Y, Kaplan A, Greetham L, Verrechia V, Halman A, Pagella S, Vyssotski AL, Illarionova A, Grinevich V, Branco T, Gross CT (2017) Prefrontal cortical control of a brainstem social behavior circuit. Nat Neurosci 20:260-270.

Furman BL, Bewick AJ, Harrison TL, Greenbaum E, Gvoždík V, Kusamba C, Evans BJ (2015) Pan-african phylogeography of a model organism, the african clawed frog "Xenopus laevis". Mol Ecol 24:909-925.

Goaillard, JM, Taylor AL, Schulz DJ, Marder E (2009) Functional consequences of animal-to-animal variation in circuit parameters. Nature Neuroscience 12: 1424-1430.

Gurdon JB, Hopwood N (2000) The introduction of Xenopus laevis into developmental biology: of empire, pregnancy testing and ribosomal genes. Int J Dev Biol 44:43-50.

Hall IC, Ballagh IH, Kelley DB (2013) The Xenopus amygdala mediates socially appropriate vocal communication signals. J Neurosci 33:1453414548.

Hall IC, Woolley SM, Kwong-Brown U, Kelley DB (2016) Sex differences and endocrine regulation of auditory-evoked, neural responses in African clawed frogs (Xenopus). J Comp Physiol A Neuroethol Sens Neural Behav Physiol 202:17-34.

Hannigan P, Kelley, D (1986) Androgen-induced alterations in vocalizations of female Xenopus laevis; Modifiability and constraints. J Comp Physiol A 158: $517-528$

Hollis DM, Boyd SK (2005) Distribution of GABA-like immunoreactive cell bodies in the brains of two amphibians, Rana catesbeiana and Xenopus laevis. Brain Behav Evol 65:127-142.

Irisarri I, Vences M, San Mauro D, Glaw F, Zardoya R (2011) Reversal to air-driven sound production revealed by a molecular phylogeny of tongueless frogs, family Pipidae. BMC Evol Biol 11:114.

Jacobson M (1984) Cell lineage analysis of neural induction: origins of cells forming the induced nervous system. Dev Biol 102:122-129.

Katz PS (2016) Evolution of central pattern generators and rhythmic behaviours. Phil Trans R Soc Lond B Biol Sci 371:20150057.

Kay JN, Hannigan P, Kelley DB (1999) Trophic effects of androgen: development and hormonal regulation of neuron number in a sexually dimorphic vocal motor nucleus. J Neurobiol 40:375-385.

Kelley DB (1980) Auditory and vocal nuclei in the frog brain concentrate sex hormones. Science 207:553-555.

Kelley DB (1982) Hormone control of female sex behavior in south african clawed frogs, Xenopus laevis. Horm Behav 1:158-174.

Kelley D (1996) Sexual differentiation in Xenopus laevis. In: The biology of Xenopus (Tinsley R, Kobel, H, eds), pp 143-176. Oxford UK: Oxford UP.

Kelley DB, Sassoon D, Segil N, Scudder M (1989) Development and hormone regulation of androgen receptor levels in the sexually dimorphic larynx of Xenopus laevis. Dev Biol 131:111-118.

Kiehn O (2016) Decoding the organization of spinal circuits that control locomotion. Nat Rev Neurosci 17:224-228. 
Kwong-Brown U, Tobias ML, Elias DO, Hall IC, Elemans CP, Kelley DB (2019) The return to water in ancestral Xenopus was accompanied by a novel mechanism for producing and shaping vocal signals. eLife 8:e39946.

Lawton KJ, Perry WM, Yamaguchi A, Zornik E (2017) Motor neurons tune premotor activity in a vertebrate central pattern generator. J Neurosci 37:3264-3275.

Leininger EC, Kelley DB (2013) Distinct neural and neuromuscular strategies underlie independent evolution of simplified advertisement calls. Proc Biol Sci 280:20122639.

Leininger EC, Kitayama K, Kelley DB (2015) Species-specific loss of sexual dimorphism in vocal effectors accompanies vocal simplification in African clawed frogs (Xenopus). J Exp Biol 218:849-857.

Lindstedt S (2014) Krogh 1929 or "the Krogh principle". J Exp Biol 217:1640-1641.

Lutz LB, Cole LM, Gupta MK, Kwist KW, Auchus RJ, Hammes SR (2001) Evidence that androgens are the primary steroids produced by Xenopus laevis ovaries and may signal through the classical androgen receptor to promote oocyte maturation. Proc Natl Acad Sci U S A 98:13728-13733.

Mallet J (2007) Hybrid speciation. Nature 446:279-283.

Marder E, Bucher D (2001) Central pattern generators and the control of rhythmic movements. Curr Biol 11:R986-R996.

Marin ML, Tobias ML, Kelley DB (1990) hormone-sensitive stages in the sexual differentiation of laryngeal muscle fiber number in Xenopus laevis. Development 110:703-711.

Mason MJ, Wang M, Narins PM (2009) Structure and function of the middle ear apparatus of the aquatic frog, Xenopus laevis. Proc Instit Acoust 31:13-21.

Mason NA, Burns KJ, Tobias JA, Claramunt S, Seddon N, Derryberry EP (2017) Song evolution, speciation, and vocal learning in passerine birds. Evolution 71:786-796.

Mesgarani N, Cheung C, Johnson K, Chang EF (2014) Phonetic feature encoding in human superior temporal gyrus. Science 343:1006-1010.

Milton RF (1946) The Xenopus pregnancy test. Br Medical J 2:328.

Missaghi K, Le Gal JP, Gray PA, Dubuc R (2016) The neural control of respiration in lampreys. Respir Physiol Neurobiol 234:14-25.

Mitra PP (2014) The circuit architecture of whole brains at the mesoscopic scale. Neuron 83:1273-1283.

Moreno N, González A (2005) Central amygdala in anuran amphibians: neurochemical organization and connectivity. J Comp Neurol 489:6991.

Moreno N, Morona R, López JM, Domínguez L, Joven A, Bandín S, González A (2012) Characterization of the bed nucleus of the stria terminalis in the forebrain of anuran amphibians. J Comp Neurol 520:330-363.

Morrell JI, Kelley DB, Pfaff DW (1975) Autoradiographic localization of hormone-concentrating cells in the brain of an amphibian, Xenopus laevis II. Estradiol. J Comp Neurol 164:63-77.

Nasipak B, Kelley DB (2012) Developing laryngeal muscle of Xenopus laevisas a model system: androgen-driven myogenesis controls fiber type transformation. Dev Neurobiol 72:664-675.

O'Connell LA, Hofmann HA (2012) Evolution of a vertebrate social decision-making network. Science 336:1154-1157.

Onimaru H, Tsuzawa K, Nakazono Y, Janczewski WA (2015) Midline section of the medulla abolishes inspiratory activity and desynchronizes preinspiratory neuron rhythm on both sides of the medulla in newborn rats. J Neurophysiol 113:2871-2878.

Paton JA, Kelley DB, Sejnowski TJ, Yodlowski ML (1982) Mapping the auditory central nervous system of Xenopus laevis with 2-deoxyglucose autoradiography. Brain Res 249:15-22.

Perez E, Villain A, Barkan, C, Hall, I, Segarra, J, Woolley SM, Kelley DB (2018) The evolution of vocal signals in frogs: evolution of vocal circuits: analyses of hybrid song features in crosses between Xenopus laevis and Xenopus petersii. 11th FENS Forum of Neuroscience, Berlin Abstract 2752.

Pérez J, Cohen MA, Kelley DB (1996) Androgen receptor mRNA expression in Xenopus laevisCNS: sexual dimorphism and regulation in laryngeal motor nucleus. J Neurobiol 30:556-568.

Phoenix CH, Goy RW, Gerall AA, Young WC (1959) Organizing action of prenatally administered testosterone propionate on the tissues mediating mating behavior in the female guinea pig. Endocrinology 65:369-382.

Potter KA, Bose, T, Yamaguchi, A (2005) Androgen-induced vocal transformation in adult female African clawed frogs. J Neurophysiol 94:415-428.

Quintana L, Sierra F, Silva A, Macadar O (2011) A central pacemaker that underlies the production of seasonal and sexually dimorphic social sig- nals: functional aspects revealed by glutamate stimulation. J Comp Physiol A Neuroethol Sens Neural Behav Physiol 197:211-225.

Ravignani A, Verga L, Greenfield MD (2019) Interactive rhythms across species: the evolutionary biology of animal chorusing and turn-taking. Ann NY Acad Sci 1453:12-21.

Rhodes HJ, Yu HJ, Yamaguchi A (2007) Xenopus vocalizations are controlled by a sexually differentiated hindbrain central pattern generator. J Neurosci 27:1485-1497.

Robertson JC, Watson JT, Kelley DB (1994) Androgen directs sexual differentiation of laryngeal innervation in developing Xenopus laevis. J Neurobiol 25:1625-1636.

Ruel TD, Kelley DB, Tobias ML (1997) Facilitation at the sexually differentiated laryngeal synapse of Xenopus laevis. J Comp Physiol A 182:35-42.

Russell WM (1955) Experimental studies of the reproductive behaviour of Xenopus laevis. Behaviour 7:113-188.

Sassoon DA, Gray GE, Kelley DB (1987) Androgen regulation of muscle fiber type in the sexually dimorphic larynx of Xenopus laevis J Neurosci 7:3198-3206.

Sassoon D, Segil N, Kelley D (1986) Androgen-induced myogenesis and chondrogenesis in the larynx of Xenopus laevis. Dev Biol 113:135-140.

Session AM, Uno Y, Kwon T, Chapman JA, Toyoda A, Takahashi S, Fukui A, Hikosaka A, Suzuki A, Kondo M, Van Heeringen SJ, van Heeringen SJ, Quigley I, Heinz S, Ogino H, Ochi H, Hellsten U, Lyons JB, Simakov O, Putnam N, et al. (2016) Genome evolution in the allotetraploid frog Xenopus laevis. Nature 538:336-343.

Seyfarth RM, Cheney DL (2008) Primate social knowledge and the origins of language. Mind Society 7:129-142.

Simpson HB, Tobias ML, Kelley DB (1986) Origin and identification of fibers in the cranial nerve IX-X complex of Xenopus laevis: Lucifer yellow backfills in vitro. J Comp Neurol 244:430-444.

Smotherman M, Kobayasi K, Ma J, Zhang S, Metzner I (2006) A mechanism for vocal-respiratory coupling in the mammalian parabrachial nucleus J Neurosci 26:4860-4869.

Sweeney LS, Kelley, DB (2014) Harnessing vocal patterns for social communication. Curr Opin Neurobiol 28:34-41.

Tobias ML, KelleyDB (1987) Vocalizations by a sexually dimorphic isolated larynx: peripheral constraints on behavioral expression. J Neurosci 7:3191-3197.

Tobias ML, Kelley DB, Ellisman M (1995) A sex difference in synaptic efficacy at the laryngeal neuromuscular junction of Xenopus laevis. J Neurosci 15:1660-1668.

Tobias ML, Viswanathan SS, Kelley DB (1998a) Rapping, a female receptive call, initiates male-female duets in the South African clawed frog. Proc Natl Acad Sci U S A 95:1870-1875.

Tobias ML, Tomasson J, Kelley DB (1998b) Attaining and maintaining strong vocal synapses in female Xenopus laevis. J Neurobiol 37:441-448.

Tobias ML, Barnard C, O’Hagan R, Horng SH, Rand M, Kelley DB (2004) Vocal communication between male Xenopus laevis. Anim Behav 67:353365.

Tobias ML, Evans BJ, Kelley DB (2011) Evolution of advertisement calls in African clawed frogs. Behaviour 148:519-549.

Tobias ML, Korsh J, Kelley DB (2014) Evolution of male and female release calls in African clawed frogs. Behaviour 151:1313-1334.

van der Heijden ME, Zoghbi HY (2018) Loss of Atoh1 from neurons regulating hypoxic and hypercapnic chemoresponses causes neonatal respiratory failure in mice. eLife 7:e38455.

Vignal C, Kelley D (2007) Significance of temporal and spectral acoustic cues for sexual recognition in Xenopus laevis. Proc Biol Sci 274:479-488.

Watson JT, Robertson J, Sachdev U, Kelley DB (1993) Laryngeal muscle and motor neuron plasticity in Xenopus laevis: analysis of a sensitive period for testicular masculinization of a developing neuromuscular system. J Neurobiol 24:1615-1625.

Wetzel DM, Kelley DB (1983) Androgen and gonadotropin effects on male mate calls in south african clawed frogs, Xenopus laevis. Horm Behav 17:388 404.

Wu KH, Tobias ML, Kelley DB (2001) Estrogen and laryngeal synaptic strength in Xenopus laevis: opposite effects of acute and chronic exposure. Neuroendocrinology 74:22-32.

Wu KH, Tobias ML, Thornton JW, Kelley DB (2003) Estrogen receptors in Xenopus: duplicate genes, splice variants, and tissue-specific expression. Gen Comp Endocrinol 133:38-49.

Xu M, Shaw KL (2019) The genetics of mating song evolution underlying 
rapid speciation: linking quantitative variation to candidate genes for behavioral isolation. Genetics 211:1089-1104.

Yager DD (1992) A unique sound production mechanism in the pipid anuran Xenopus borealis. Zool J Linn Soc 104:351-375.

Yamaguchi A, Kelley DB (2000) Generating sexually differentiated vocal patterns: laryngeal nerve and EMG recordings from vocalizing male and female african clawed frogs (Xenopus laevis). J Neurosci 20:1559-1567.

Yamaguchi A, Cavin Barnes J, Appleby T (2017) Rhythm generation, coordination, and initiation in the vocal pathways of male African clawed frogs. J Neurophysiol 117:178-194.

Yamaguchi A, Woller DJ, Rodrigues P (2018) Development of an acute method to deliver transgenes into the brains of adult Xenopus laevis. Front Neural Circuits 12:92.

Yang EJ, Nasipak BT, Kelley DB (2007) Direct action of gonadotropin in brain integrates behavioral and reproductive functions. Proc Natl Acad Sci U S A 104:2477-2482.

Yin H, Price F, Rudnicki MA (2013) Satellite cells and the muscle stem cell niche. Physiol Rev 93:23-67.
Yu HJ, Yamaguchi A (2010) Endogenous serotonin acts on 5-HT2C-like receptors in key vocal areas of the brain stem to initiate vocalizations in Xenopus laevis. J Neurophysiol 103:648-658.

Zornik E, Kelley DB (2007) Breathing and calling: neuronal networks in the Xenopus laevis hindbrain. J Comp Neurol 501:303-315.

Zornik E, Kelley DB (2008) Regulation of respiratory and vocal motor pools in the isolated brain of Xenopus laevis. J Neurosci 28:612621.

Zornik E, Kelley DB (2011) A neuroendocrine basis for the hierarchical control of frog courtship vocalizations. Front Neuroendocrinol 32: 353-366.

Zornik E, Yamaguchi A (2011) Vocal pathway degradation in gonadectomized Xenopus laevis adults. J Neurophysiol 105:601-614.

Zornik E, Yamaguchi A (2012) Coding rate and duration of vocalizations of the frog, Xenopus laevis. J Neurosci 32:12102-12114.

Zornik E, Katzen AW, Rhodes HJ, Yamaguchi A (2010) NMDARdependent control of call duration inXenopus laevis. J Neurophysiol 103: 3501-3515. 